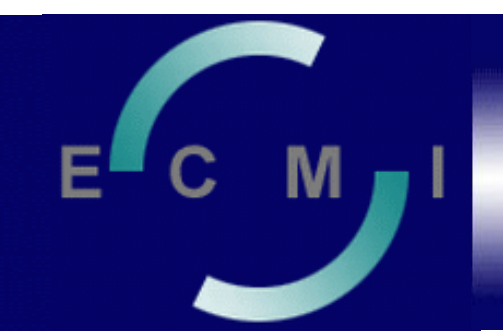

ECMI Research Report

No. 5/April 2010

\title{
Shaping Reforms and Business Models for the OTC Derivatives Market Quo vadis?
}

\section{Diego Valiante}

\begin{abstract}
Now that the worst of the financial storm is over, regulators are setting new strategies to deal with the systemic importance of the $€ 427$ trillion ( $\$ 604$ trillion) over-the-counter (OTC) derivatives market. This paper explores the three major sources of disruptive effects in OTC derivatives: liquidity, counterparty risk and legal uncertainty. These risks affect the value chain of a typical derivative transaction and weaken the economic and legal rationale behind their widespread use. On the policy side, commitments have been made at G-20 level to draft uniform rules on a global scale "to build a safer financial system". This paper finds, however, that in practice, the EU and US proposals lay out divergent roads to meet common objectives and the author warns that such divergences may encourage regulatory and supervisory arbitrage. Policy options currently under discussion may need further revision. For instance, access to network clearing infrastructures, such as CCPs, can only be made available to a restricted group of eligible derivative products. Mechanisms of adverse selection and moral hazard, then, may at any time affect the efficient functioning of these crucial infrastructures for financial markets.
\end{abstract}

Keywords: OTC derivatives, central counterparty clearing (CCP), data repositories, collateral management, electronic trading platform, exchange, market transparency, systemic risk, financial and securities regulation, corporate finance, capital markets, financial crisis

JEL Classification: G10, G15, G18, G20, G24, G28

ISBN 978-92-9079-981-8

Available for free downloading from the ECMI and CEPS website

(www.eurocapitalmarkets.org; www.ceps.eu)

(c) Copyright 2010 Diego Valiante. All rights reserved. 



\section{Contents}

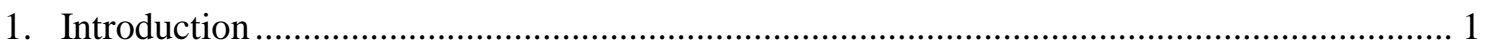

2. Setting the scene

3. Size and shape of the OTC derivatives market …............................................................... 3

4. Legal and economic views of growth and concentration .................................................... 7

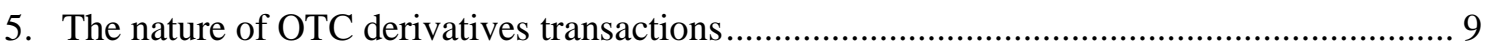

6. Shedding light on the OTC derivatives' chain value: A cost-benefit analysis ...................... 12

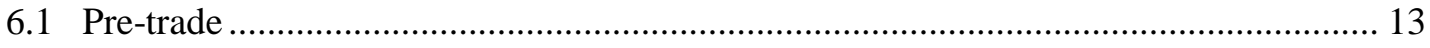

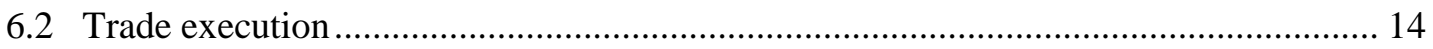

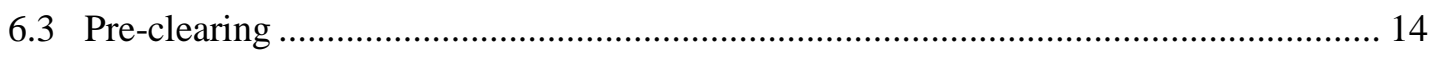

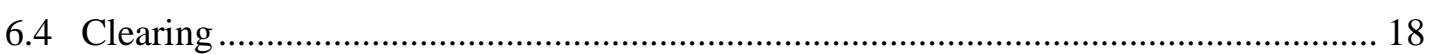

6.5 Central Counterparty Clearing: Benefits and risks for the OTC derivatives market..... 22

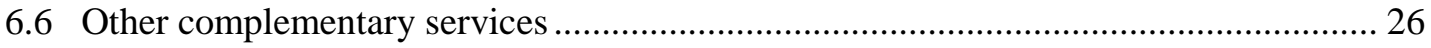

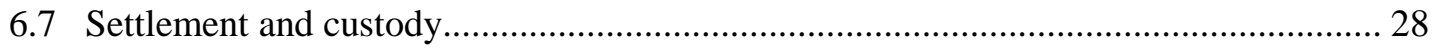

7. The OTC derivatives market and the financial crisis ......................................................... 29

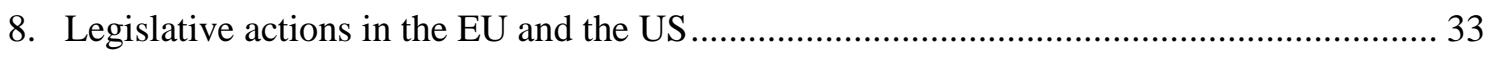

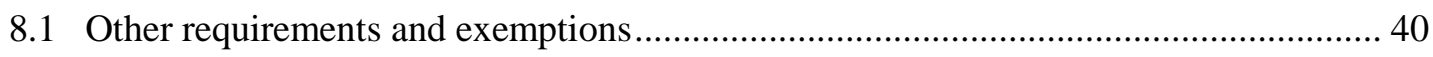

9. Prospects for the OTC derivatives market: Four scenarios ............................................... 45

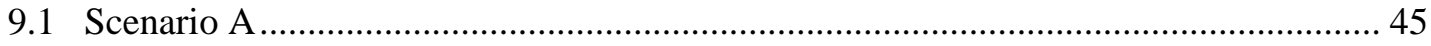

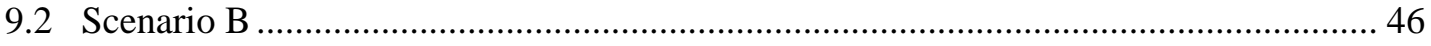

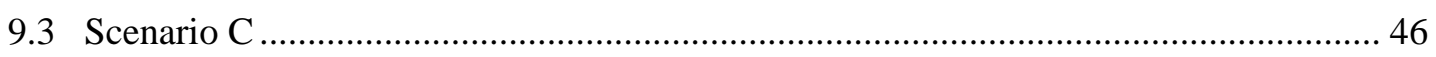

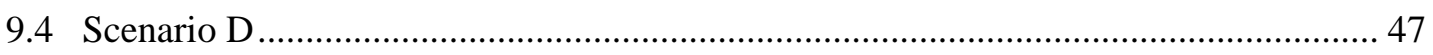

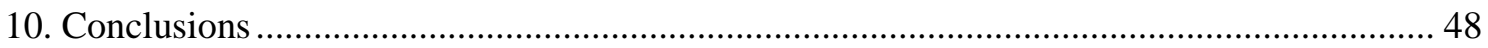

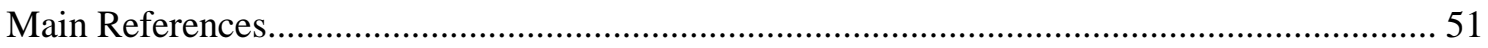

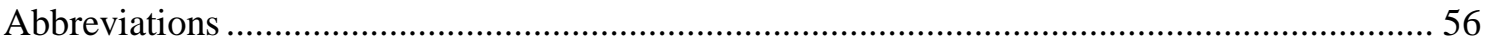




\section{List of Tables}

Table 1. Overview of the OTC derivatives market (US, EU and global) ................................... 6

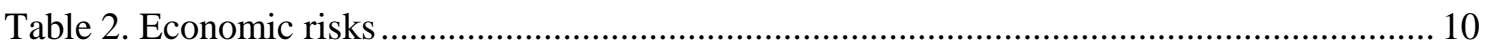

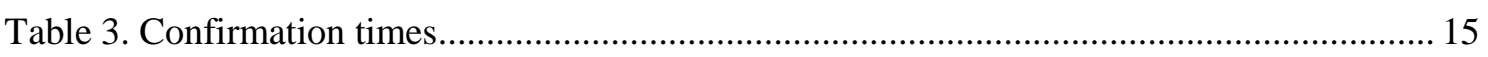

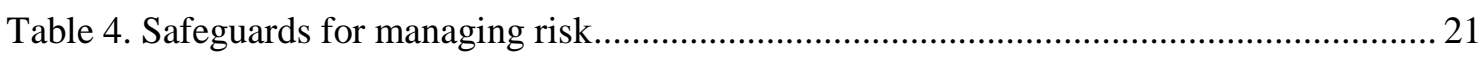

Table 5. US and EU OTC derivatives proposals: A comparison of key features ........................ 42

\section{List of Figures}

Figure 1. Notional value outstanding OTC contracts ( $€$ billion) ................................................. 4

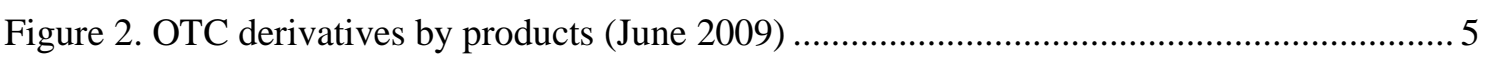

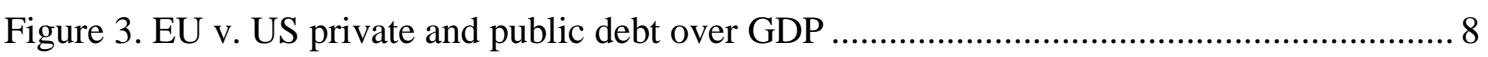

Figure 4. Dealers, financial and non-financial institutions

( $\$$ billion, notional outstanding - June 2009) .............................................................. 9

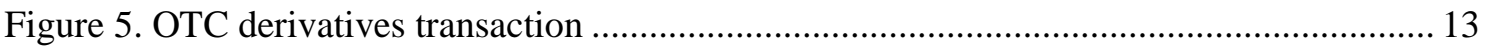

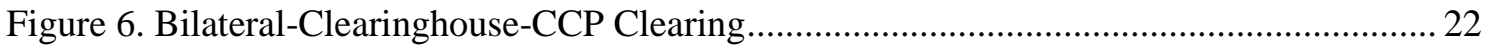

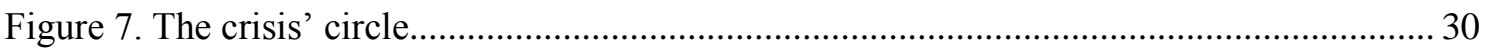

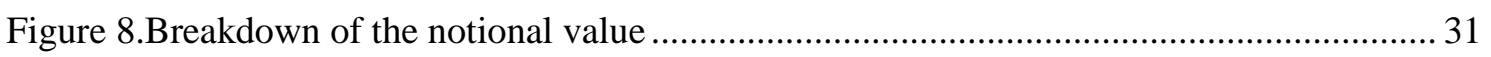

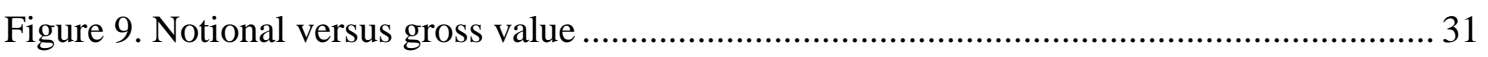

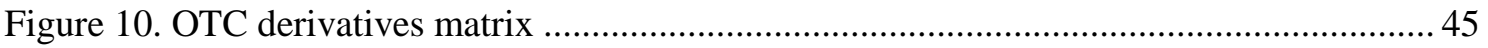

\section{List of Boxes}

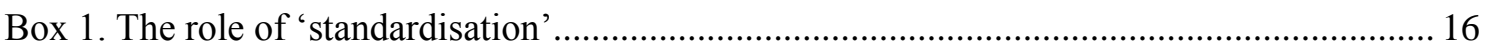

Box 2. What is the role of trade repositories? Competition vs. centralisation ............................ 27

Box 3. The Volcker rule: A big cloud over the OTC derivatives market ..................................... 50 


\title{
Shaping Reforms and Business Models for the OTC Derivatives Market Quo vadis?
}

\author{
ECMI Research Report No. 5/April 2010 \\ Diego Valiante*
}

\section{Introduction}

Riding the wave of public sentiment and acknowledging the need to overhaul financial markets, regulators on both sides of the Atlantic are drafting new rules for derivatives, which are financial instruments whose value (price of the contract) is derived from the value of an underlying asset (e.g. equity, bond or commodity) or market variable (e.g. interest rate, credit risk, exchange rate or stock index). ${ }^{1}$ They are typically traded over-the-counter (OTC), i.e. directly between two parties without going through an organised exchange or other intermediary. To date, the market has largely been unregulated, ${ }^{2}$ like other innovative areas of financial markets, although some market players have been recently affected by regulation and market initiatives through capital requirements and stronger market discipline. ${ }^{3}$ As a result of increased systemic risks ${ }^{4}$ and financial instability attributed to counterparties' risks of failure (and so-called 'cascade effects'), however, forthcoming regulation aims to shape a new trading and post-trading landscape for the OTC derivatives market and related business models adopted by firms.

However, despite some specific issues (e.g. uncertainty over real uncollateralised exposures to OTC derivatives after the collapse of Lehman Brothers), the trading and post-trading infrastructure of the OTC derivatives market showed strong resilience in dealing with big counterparties' failures during the financial turmoil. It processed trillions of trades with minor repercussions for the safety of the global financial system, even though state intervention was needed for some pivotal financial institutions, due to their inability to face soaring counterparty risks as a result of the financial crisis (e.g. AIG). Current proposals at EU and US level are strenuously trying to push derivatives 'on-the-counter', questioning the future prospects for trade execution and clearing and settlement platforms. On the one hand, there is strong pressure

\footnotetext{
* Diego Valiante $(\mathrm{PhD})$ is researcher at the European Capital Markets Institute and the Centre for European Policy Studies. Comments from Cinzia Alcidi, Piero Cinquegrana, Godfried De Vidts, Toni Freeman, Christian Held, Karel Lannoo, Barbara Matthews, Richard Metcalfe, Donald Ricketts and Ingrid Vogel are gratefully acknowledged.

1 See European Commission, "Derivatives Markets", FAQs (available at http://europa.eu/rapid/pressReleasesAction.do?reference=MEMO/09/314\&format=HTML\&aged=0\&lang

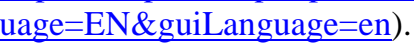

${ }^{2}$ US Treasury Department (2009, p. 47).

${ }^{3}$ In particular, some players - such as banks - fall under Basel II agreements, which impose a large set of rules concerning capital requirements, supervision and market discipline.

${ }^{4}$ An activity or financial institution may involve relevant risks for its 'systemic' size, degree of leverage and level of interconnection in the global financial system. In effect, failures to capture systemic risks can be caused by methodologies that do not take into account their role in financial systems, network externalities and the effect of pro-cyclical behaviour fuelled by periods in which the measured risk is particularly low. See Goodhart et al. (2008, Foreword); FSA (2009, p. 23).
} 


\section{$2 \mid$ Diego Valiante}

for standardisation and data reporting, and on the other, there is an underlying trade-off with customisation and liquidity, which can be a source of instability in the long run.

This paper is divided into four parts.

The first part (sections 2-4) explores three major aspects of the OTC derivatives market: 1) the economic reasons behind the use of derivatives, 2) the systemic importance of this market with a detailed analysis of the level of risk concentration and its impact and 3) the legal and economic reasons behind the rapid and huge growth of this financial market.

The second part (sections 5-6) deals with the micro aspects of the derivatives market: 1) the nature of the transactions and legal and economic risks involved, 2) the value chain with a focus on the financial infrastructure behind derivative transactions and 3) issues currently under debate such as standardisation, the risks and benefits of CCPs and competitive data repositories.

In the third part (section 7), we analyse the general impact of the recent financial crisis on the market for OTC derivatives, highlighting the major sources of concerns.

In the final part (sections 8-9), we describe the new legislative proposals under debate in the EU and the US and assess the future prospects of this market. On that basis, we then draw some policy conclusions.

\section{Setting the scene}

The origins of derivative financial instruments date back to ancient times. ${ }^{5}$ Over-the-counter derivatives are usually bilateral, privately negotiated contracts that can be settled in cash or physically (Culp, 2009, p. 5). Therefore, they are customised and off-exchange, in order to meet specific needs of the involved counterparties (ECB, 2009). By some they might be seen as a 'bet'. However, investing in a safe German Bund is also equivalent to betting on the low probability of a surge in the rate of inflation. "It is a bet on a bet", typically used to hedge another position in the market.

OTC derivatives can be classified into four categories: futures (and forwards), options, swaps and exotic instruments. ${ }^{6}$ Transactions are generally 'customised', i.e. tailored to a firm's idiosyncratic risks.

A derivatives transaction may be set up for any one of four different reasons: hedging, funding, speculation and arbitrage.

Firstly, firms or financial institutions seek hedged positions in case they cannot directly bear that risk. An example is the protection, through currency options, against currency risk of a relevant investment in a foreign country and currency. Hence, the protection buyer transfers the economic risk related to a market variable (e.g. a possible surge in the price of oil or a currency trend) to other firms or financial institutions willing and effectively prepared to bear the risk (protection seller). In this way, the risk will not be eliminated but simply transferred to other firms that are better equipped to handle it. The possibility to transfer economic risk is linked to the presence of a resilient and safe market infrastructure, where players provide sufficient collateral and countercyclical requirements against the potential default of the counterparty. The use of derivatives in the regular activities of many financial and non-financial institutions has

\footnotetext{
${ }^{5}$ See Swan (2000) for a 4,000 year history of derivatives, dating back to the ancient Middle East.

${ }^{6}$ Recently, the Committee of European Securities Regulators (CESR) has drawn up a classification of these instruments as: options, warrants, futures, contracts for difference and total return swaps, spreadbets, swaps, credit default swaps and complex derivatives. See, in general, CESR (2009).
} 
also been widespread during the recent financial crisis, as they are essential tools allowing investors to hedge against a worldwide market.

Secondly, derivatives can be a tool to redistribute funding between financial institutions or within non-financial institutions in a way that best suits the company's financial needs. For instance, a financial institution issues coupon bonds and decides to rearrange the payments of these periodic coupons with a specific trajectory in order to avoid risks or simply to redistribute risks in a certain way.

Thirdly, derivatives may be also used to speculate on a specific market variable or company trend. As stated by Grossman \& Stiglitz (1980), "prices reflect the information of informed individuals (arbitrageurs) but only partially, so that those who expend resources to obtain information do receive compensation". Speculative use of derivatives thus includes institutions or traders who invest in information in order to get higher returns from the market. Their trading activity increases the liquidity in the market and - if the information proves to be wrong speculation may potentially favour 'noise trading, ${ }^{7}$ which can only affect prices for a short time. ${ }^{8}$ In effect, trading against fundamentals is costly, even though it is possible and in the short-run it can be even successful (De Long et al., 1990)! In the end, noise trading helps to create uncertainty on prices, but, at the same time, this leads more uninformed traders to search for information (as they will be compensated), pushing liquidity in the market and improving price discovery (the 'equilibrium of disequilibrium'). Without speculation (or better called 'informed trading'), there would be no counterparties for hedgers. Speculation or informed trading is frequently confused with the intent to manipulate market prices, as the border between investing to obtain and use outside and visible information has, from a regulatory point of view, a 'thin' border with illegal actions intended to obtain inside and sensible information. Therefore, attention should be drawn to the way in which information circulates and how fast it changes in ways that can generate advantages for few participants. Regulators and policy-makers should be less concerned with the particular use of a product or technique as such.

Last but not least, using derivatives as a tool for arbitrage facilitates the mechanism of price formation, aligning in a short interval of time bid/ask spreads. Arbitrageurs operate with a short horizon and are reasonably risk-averse. They aim at making profits without taking relevant risks. Their role is limited to making price formation more efficient, while their systemic impact is not relevant. Frequently, their behaviour can be seen as a response to noise trading rather than as trading on fundamentals (De Long et al., 1990). The joint action of arbitrageurs and speculators supports markets in reaching their 'absorptive capacity' (critical level of liquidity). ${ }^{9}$ Derivatives instruments and their multiple uses may facilitate efficient market functioning and the revelation of critical information. ${ }^{10}$ In effect, CDS (credit default swap) spreads are widely used as a tool for risk management in order to price the credit risk of a specific counterparty.

\section{Size and shape of the OTC derivatives market}

In the last decade, the OTC derivatives market evolved into the biggest global market, in size and interconnection between financial institutions. This market showed an impressive rate of

\footnotetext{
${ }^{7}$ Uninformed investors buying and selling financial securities at irrational prices, thus creating noise (strange movements) in the price of securities.

${ }^{8}$ Friedman (1953, p. 175 in De Long et al. [1990]) wrote: "that ... speculation is ... destabilizing ... is largely equivalent to saying that speculators lose money, since speculation can be destabilizing in general only if speculators on ... average sell ... low ... and buy ... high".

${ }^{9}$ See, in general, Pagano (1989, pp. 255-274).

${ }^{10} \mathrm{See}$, in general, Duffie \& Rahi (1995).
} 


\section{4 | Diego Valiante}

growth in the last decade, reaching its peak in mid-2008 with more than $€ 433$ trillion ( $\$ 680$ trillion) of gross notional value ${ }^{11}$ for outstanding contracts. In effect, the over-the-counter derivatives market grew between June 2001 and June 2008 by circa 535\% at the annual weighted average rate of $33.68 \%$ (in \$).

\section{Figure 1. Notional value outstanding OTC contracts ( $€$ billion)}

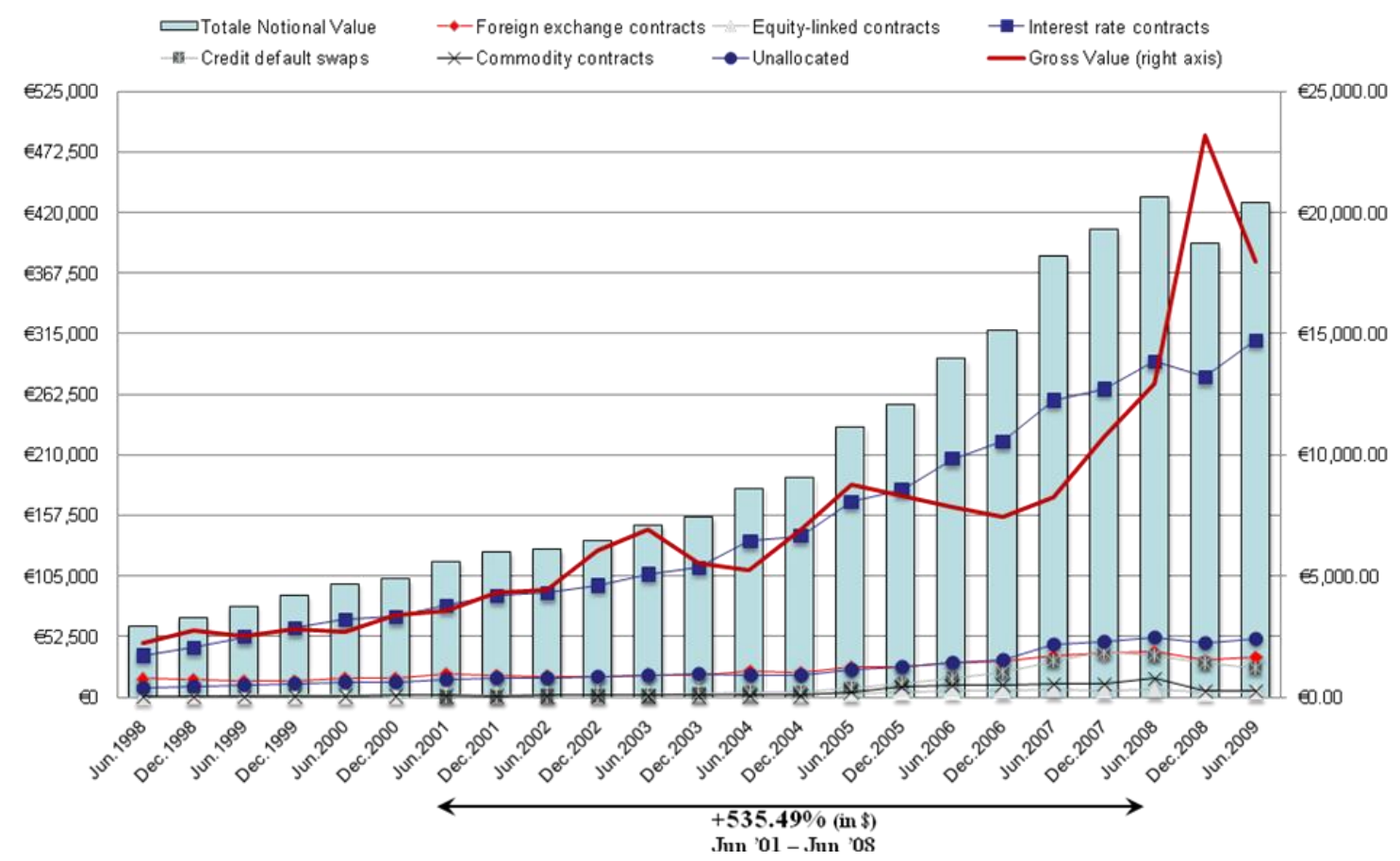

Source: BIS (2009) and ISDA.

However, the notional value dropped by $20 \%$ to around $€ 393$ trillion (around $\$ 600$ trillion) in the second half of 2008, as an immediate result of the financial crisis and the reduced activity of financial institutions. The downward trend did not last long, however, and in the first half of 2009 the market started to grow again by $10 \%$ to $€ 427$ trillion ( $\$ 604$ trillion), confirming its systemic importance. In effect, the market has recently demonstrated its impressive ability to return to the same level it had reached at the end of 2007.

The costs of replacement of these contracts (i.e. gross market value) have showed a different trend, though. From June to December 2008, it soared by 58.3\% to $€ 23$ trillion ( $\$ 32$ trillion), as consequence of the increased risk due to the financial crisis (risks of adverse selection after Lehman's default) and the consequent impact on liquidity and market value (see figure above). This acceleration shows the risk of high-volatility of the market value in derivatives (as a 'leverage effect'), due to moves in the underlying markets. By contrast, in the first half of 2009, the gross market value dramatically bounced back by $21 \%$, due to the recovery of the underlying markets and the improved global economic outlook.

\footnotetext{
${ }^{11}$ The notional value (or simply 'notional') consists of the face value of the OTC derivatives contracts, while the gross market value is the cost of replacing the contracts at current market prices. The latter is calculated by subtracting the market value and redundancies of the OTC contracts to the notional; see BIS (2009). In addition, 'gross market value' figures do not include netted value of positive and negative cost for replacement of contracts with the same counterparty.
} 
Despite the fact that derivatives typically have a very large notional amount, the real market value of their exposure is much lower and, in some cases, it has much less systemic impact than expected. For instance, in the credit default swaps (CDSs) market, the bankruptcy of Lehman Brothers Holdings Inc. implied actual net fund transfers from protection sellers to protection buyers of only $\$ 5.2$ billion (notional $\$ 72$ billion) - a much smaller sum than the huge losses posted when Lehman collapsed in September 2008 - and \$500 billion in market participants' exposure from Lehman Brothers on CDSs was successfully closed out. ${ }^{12}$ Nevertheless, the rapid growth of credit and equity-linked derivatives - in the last five years - may plausibly reflect the need for improved market-based mechanisms of signalling risk and risk protection against more complex credit exposures (e.g. the use of credit default swaps) and for instruments less volatile than equities markets (e.g. equity-linked derivatives).

Figure 2. OTC derivatives by products (June 2009)

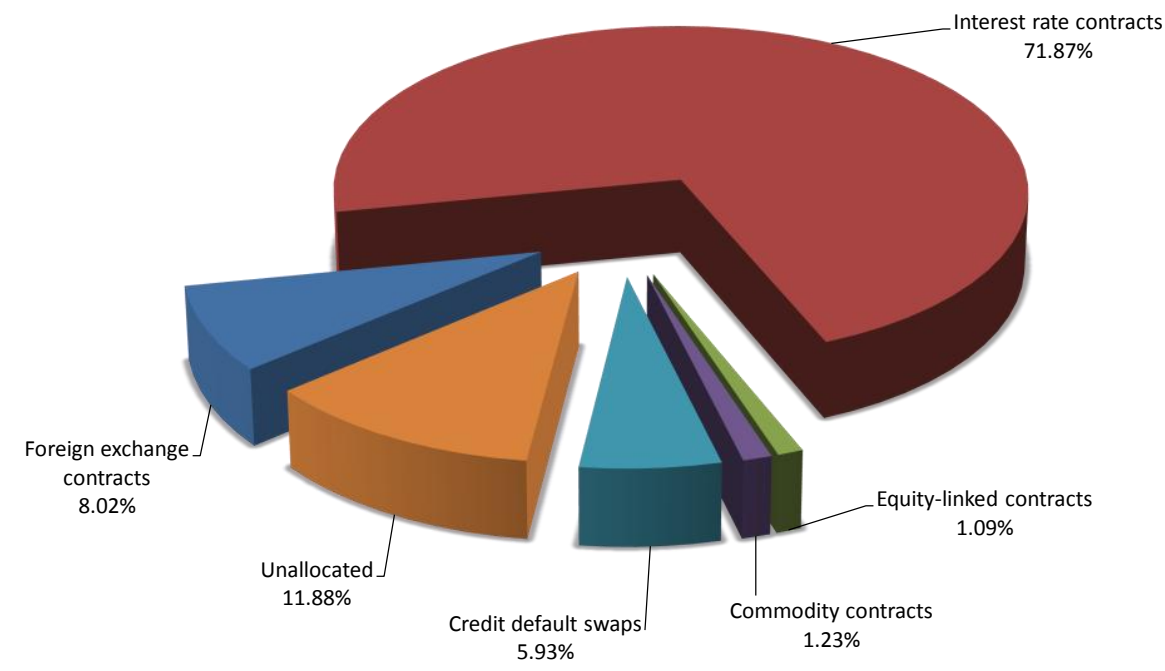

Source: BIS (2009).

Statistics from the Bank for International Settlements (BIS) show that in the first half of 2009 the worst period of the recent financial crisis - the use of interest rate derivatives increased significantly (protection to external factors), while the use of CDSs decreased by circa $14 \%{ }^{13}$ (around $\$ 36$ trillion $^{14}$ or $€ 25.5$ trillion). This market did not drastically shrink, as centralisation of CDS clearing was gradually replacing the current infrastructure. In addition, the International Swaps and Derivatives Association (ISDA) estimated that the total market value of the circa $€ 425$ trillion ( $\$ 600$ trillion) in gross notional outstanding OTC derivatives is around $\$ 4$ trillion, after netting and eliminating redundancies. ${ }^{15}$ BIS statistics confirm as well that the gross credit

12 See press releases of the Depository Trust in Clearing Corporation (DTCC), 22 October 2008 (http://www.dtcc.com/news/newsletters/dtcc/2008/oct/lehman_credit_event.php) and 30 October 2008 (http://www.dtcc.com/news/press/releases/2008/dtcc closes_lehman_cds.php).

${ }^{13}$ The increasing use of complementary services, such as portfolio compression services, may have given relevant support to reduce the notional value (see Duffie et al., 2010).

${ }^{14}$ In February 2009, the DTCC reported that the gross notional value of outstanding CDS contracts in its data warehouse (collecting circa $90 \%$ of all CDS trades) was $\$ 25.5$ trillion; see DTCC (http://www.dtcc.com/products/derivserv/data_table_i.php).

15 These estimates were published by IOSCO in its last report on unregulated financial markets; see IOSCO (2009). ISDA also releases data on derivatives on a semi-annual basis (see http://www.isda.org/statistics/pdf/ISDA-Market-Survey-historical-data.pdf). 
exposure, ${ }^{16}$ by the end of June 2009 , was around $\$ 4$ trillion ( $\$ 3.7$ trillion), excluding CDSs traded outside the United States.

Concerning the market share of financial institutions and the overall concentration rate, US insured commercial banks and financial holdings, which represent almost one-half of the total global market for OTC derivatives, slightly increased the total volume of transactions in the first half of 2009 (also with more netting activities). ${ }^{17}$ Almost all OTC derivatives transactions in the US are subscribed by five financial services holdings (and commercial banks). ${ }^{18}$ This aspect does not necessarily imply action from the competition policy side, since it needs deeper analysis and a breakdown of data by products. However, the table below provides a valuable overall picture of the OTC derivatives markets for its potential implications in terms of financial stability.

Table 1. Overview of the OTC derivatives market (US, EU and global)

\begin{tabular}{|c|c|c|c|c|c|c|c|}
\hline \multicolumn{3}{|c|}{ Financial institutions } & \multicolumn{2}{|c|}{$\begin{array}{l}\text { Shares of global OTC } \\
\text { derivatives market } \\
\text { (31 Dec 2008; } € \text { mil) }\end{array}$} & \multicolumn{2}{|c|}{$\begin{array}{l}\text { Shares of global OTC } \\
\text { derivatives market } \\
\text { (30 June 2009; } € \text { mil) }\end{array}$} & \multirow{2}{*}{$\frac{\Delta}{-11.45 \%}$} \\
\hline \multirow{5}{*}{ US } & JPMorgan Chase & Notional & $€ 61,049,613$ & $14.35 \%$ & $€ 54,058,888$ & $12.64 \%$ & \\
\hline & Bank of America Corp. & Notional & $€ 26,396,816$ & $6.21 \%$ & $€ 50,234,425$ & $11.74 \%$ & $+90.3 \%$ \\
\hline & Goldman Sachs Group Inc. ${ }^{a}$ & Notional & $€ 21,366,658$ & $5.02 \%$ & $€ 32,472,198$ & $7.59 \%$ & $+51.98 \%$ \\
\hline & Morgan Stanley & Notional & $€ 40,777,669^{\mathrm{c}}$ & $9.44 \%$ & $€ 27,188,353$ & $6.36 \%$ & $-33.33 \%$ \\
\hline & Citigroup Inc. & Notional & $€ 21,740,817$ & $5.11 \%$ & $€ 21,893,652$ & $5.12 \%$ & $+0.7 \%$ \\
\hline \multirow{9}{*}{$\mathbf{E U}$} & Top 5 institutions & Notional & $€ 171,331,574$ & $40.13 \%$ & $€ 185,847,515$ & $43.44 \%$ & $+8.47 \%$ \\
\hline & Tot. US OTC derivatives & Notional & $€ 179,886,265$ & $42.14 \%$ & $€ 194,419,086$ & $\mathbf{4 5 . 4 5 \%}$ & $+8.08 \%$ \\
\hline & Deutsche Bank Group & $\begin{array}{l}\text { Notional } \\
\text { Gross }\end{array}$ & $\begin{array}{c}€ 49,189,619 \\
\text { (notional) }\end{array}$ & $11.56 \%$ & $\begin{array}{l}€ 1,500,211 \\
\quad \text { (gross) }\end{array}$ & $8.36 \%$ & $-37.42 \%^{c}$ \\
\hline & Barclays Group & Notional & $€ 36,917,079$ & $8.68 \%$ & $€ 37,059,196^{\mathrm{d}}$ & $8.66 \%$ & $+0.39 \%$ \\
\hline & RBS Group & Gross & $€ 1,958,768^{\mathrm{d}}$ & $8.04 \%$ & $€ 1,220,081^{\mathrm{d}}$ & $6.8 \%$ & $-37.71 \%$ \\
\hline & UBS & Notional & $€ 31,096,296$ & $7.31 \%$ & $€ 29,820,875^{\mathrm{d}}$ & $6.97 \%$ & $-4.1 \%$ \\
\hline & Credit Suisse & Notional & $€ 25,957,778$ & $6.10 \%$ & $€ 28,882,280$ & $6.75 \%$ & $+11.07 \%$ \\
\hline & HSBC Group & Gross & $€ 979,359^{d}$ & $4.02 \%$ & $€ 679,719^{d}$ & $3.79 \%$ & $-30.6 \%$ \\
\hline & BNP Paribas Group & Notional & $€ 22,536,650$ & $5.30 \%$ & $\mathrm{n} / \mathrm{a}$ & - & - \\
\hline & Top 6 EU institutions & - & - & $51.02 \%$ & - & $41.33 \%$ & - \\
\hline & Tot. top US-EU institutions ${ }^{b}$ & - & - & $91.15 \%$ & - & $84.77 \%$ & - \\
\hline & Tot. global OTC derivatives ${ }^{\text {b }}$ & Gross & $€ 24,350,752$ & $100 \%$ & $€ 17,951,003$ & $100 \%$ & - \\
\hline & Tot. global OTC derivatives ${ }^{\mathrm{b}}$ & Notional & $€ 425,352,376$ & $100 \%$ & $€ 427,778,185$ & $100 \%$ & - \\
\hline
\end{tabular}

a By the end of 2008, Goldman Sachs' data include only the bank division, not the whole Group. By June 2009, data include the whole Group's exposure to OTC derivatives. Morgan Stanley was not included in the OCC report, as they did not disclose their exposure at the end of 2008 .

${ }^{\mathrm{b}}$ The percentage per institution is a result of the comparison between the values at the date of 31 Dec 2008 for the holding company with the notional and gross amount at 31 Dec 2008, as calculated by BIS in May 2009. We did not use the data updated to November 2009, as also the single exposure should be updated to November 2009 for the positions held at the end of 2008.

${ }^{c}$ Author's estimation based on the fair value of OTC derivatives contracts.

${ }^{16}$ Gross credit exposure can be defined as the "gross value of contracts that have a positive market value after taking account of legally enforceable bilateral netting agreements" (see Cecchetti et al., 2009, p. 57).

${ }^{17}$ See Office of the Comptroller of the Currency (OCC) - Administrator of National Banks, "OCC's Quarterly Report on Bank Trading and Derivatives Activities - Second Quarter 2009" (available at http://www.occ.treas.gov/ftp/release/2009-114a.pdf).

${ }^{18}$ See ibid. and Fitch Ratings (2009). 


\footnotetext{
d Author's estimation of the OTC part from available data. Looking at past data, for RBS and HSBC, we assume that the OTC derivatives exposure is the $95 \%$ of the total exposure.

Sources: OCC (2009), BIS (2009) and author's own estimations.
}

As shown in Table 1, the market for OTC derivatives is still highly concentrated and far bigger than the exchange-traded side of the market, ${ }^{19}$ with relevant implications in terms of systemic risk and financial stability (see below). The concentration of the US OTC derivatives market is still increasing, due to the completion of winding up and acquisitions of relevant financial institutions (such as Lehman Brothers, Bear Stearns and Merrill Lynch). In the EU, conversely, the fragmentation of derivatives exposures is increasing, and big players, such as Deutsche Bank, HSBC and RBS, are drastically reducing their positions in OTC derivatives in their attempts to deal with the huge losses they have suffered and state intervention through refocusing their activities around their core retail business.

\section{Legal and economic views of growth and concentration}

The growth per category has been steady and in line with the background trend (see Figure 2). For instance, CDSs have increased at a slightly faster pace in the last four years, but at a lower level than that perceived by the public opinion. This implies that the distribution of derivatives transactions between the different instruments has remained constant and there is no evidence that a particular use of derivatives (such as speculation) has increased in comparison to other uses (such as hedging). Legal and economic explanations can be identified as the rationale behind the growth and concentration of the OTC derivatives market. ${ }^{20}$

On the one hand, a legal explanation for the growth of derivatives, arduously defended by Prof. Lyn Stout (2009), is the gradual dismantling of the common law rule known as 'rule against difference', which states that the use of derivatives is legal only if parties hold the underlying asset. The Financial Services Act of 1986 in the UK and the Commodity Futures Modernization Act of 2000 in the US repealed this binding rule declaring all financial derivatives legally enforceable, boosting the uncontrolled growth of the derivatives market (Stout, 2009). This explanation does not seem well-founded as arbitrage between the UK and US markets due to this legal discrepancy in such a long time frame (1986-2000) did not occur. Instead, those legal acts assured legal certainty and enforceability of contracts to the market, helping parties to hedge against counterparty risk and to provide efficient information to the market through 'informed trading' (information revelation). For instance, the most liquid CDS spreads - usually on 5-year CDSs - are commonly known as efficient risk management tools. In effect, they are widely used to evaluate and price credit risk, especially in the banking sector. Derivatives transactions executed without holding the underlying assets are crucial to guaranteeing the liquidity of these products and to disseminate material information in the market through the impact on spreads of naked 'informed' transactions.

On the other hand, current capital requirements allowed many financial institutions to purposefully accumulate huge positions on some derivatives instruments as a way to reduce their overall regulatory capital (through the extensive use of VaR measures for regulatory purposes; see Goodhart, 2008; FSA and HM Treasury, 2009). These measures have stimulated further growth and concentration in this market.

\footnotetext{
19 The White Paper drafted by Deutsche Borse Group (2009) estimates the notional outstanding for exchange-traded derivatives being around $10 \%$ of the global derivatives market. Our calculations confirm this size (9.9\%); see ECMI (2009).

${ }^{20}$ On the evolution of OTC markets in the last years, see also Yallop (2008).
} 


\section{$8 \mid$ Diego VALiante}

The economic justification of this dramatic expansion lies in the surge of the underlying markets and the improved mechanisms for dealing with risks and netting (e.g. CCP). The growth of the OTC derivatives market is widely recognised as a sign of market innovation which helped to free resources in order to support economic growth - and a tool closely related to specific areas of financial markets. For instance, the uncontrolled growth of lending and securitisation markets increased the exposure of financial institutions in the market (see Figure 3 ), inducing linked markets such as derivatives to increase as well in order to efficiently handle risks of these huge positions. The important growth of exposures induced financial firms to increase protection through customised derivatives transactions, such as for instance interest rate swaps to hedge interest rate fluctuations or credit default swaps to buy insurance in order to protect their exposure on CDOs (collateralised debt obligations).

Figure 3. EU v. US private and public debt over GDP

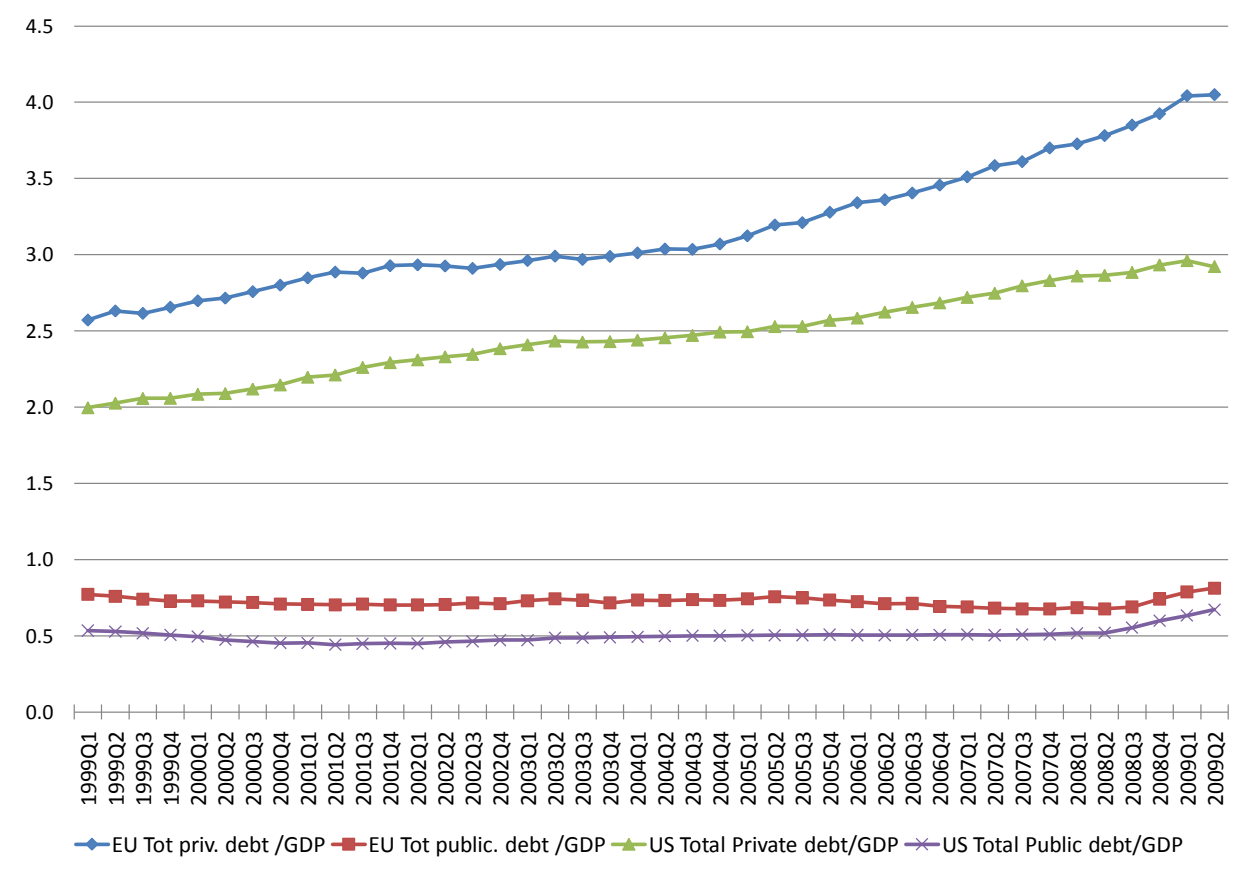

Sources: ECB and FED databases.

In the last decade, the growth of the private and public debt (see figure above) involved an inevitable increase of the exposure to counterparty risk and cash flow management risk (e.g. risk of temporary insolvency on their own exposures). Derivatives are an effective tool to manage those risks. For instance, a big lending institution may hedge its relevant exposure (e.g. CDOs, bond issuance) with a specific counterparty (also another financial institution) by buying protection through a CDS on the debt or on the reference entity, even in the 'naked' version. A financial institution or government agency would also be willing to purchase a derivative in order to smooth in the short run the financial impact on the income statement of a bond issuance and to have more liquidity for immediate investments. Therefore, the impact of public and private debt plus the growth of other underlying markets (e.g. commodities) increased the need to transfer certain financial risks through instruments that are mainly designated and traded over-the-counter. The use of these instruments amplified interconnections between financial institutions, which are frequently transactions involving derivative instruments.

In conclusion, the increasing use of advanced netting and other compression services has reduced the size of the notional value and its impact on financial institutions' balance sheets 
(Duffie et al., 2010). ${ }^{21}$ So these services have made it feasible to create huge order books in terms of notional value, while the 'real' exposure is much less than that. Dealers thus can accumulate collateral against the netted value (not the gross value), with a greater possibility to increase their share of the market and its concentration. Deutsche Borse Group (2009) estimated the impact of netting (excluding cash collateral) on bilateral OTC derivatives exposures at $85 \%$ and, through the use of CCP, at 99\% (for products on-exchanges). Thus, if the amount of the notional value is 100 , netting can reduce this value to 15 or even to 1 . These size-reduction services generate economies of scale and lead end-users to deal with one or only a few counterparties (making the market become more concentrated in the process through fewer dealers), reducing their burdens in the transaction (collateral, capital requirements, etc.) and reaping the benefits of centralised solutions (see next section).

\section{The nature of OTC derivatives transactions}

OTC derivatives transactions typically involve dealers and other financial institutions. Nonfinancial institutions represent almost $10 \%$ of the market (see figure below), although many of them regularly make use of customised derivatives transactions to hedge their core business risks (especially with FX derivatives). However, non-financial institutions are a much higher percentage of users of derivatives products centrally cleared (around 20\%). ${ }^{22}$

Figure 4. Dealers, financial institutions and non-financial institutions (\$ billion, notional outstanding - June 2009)

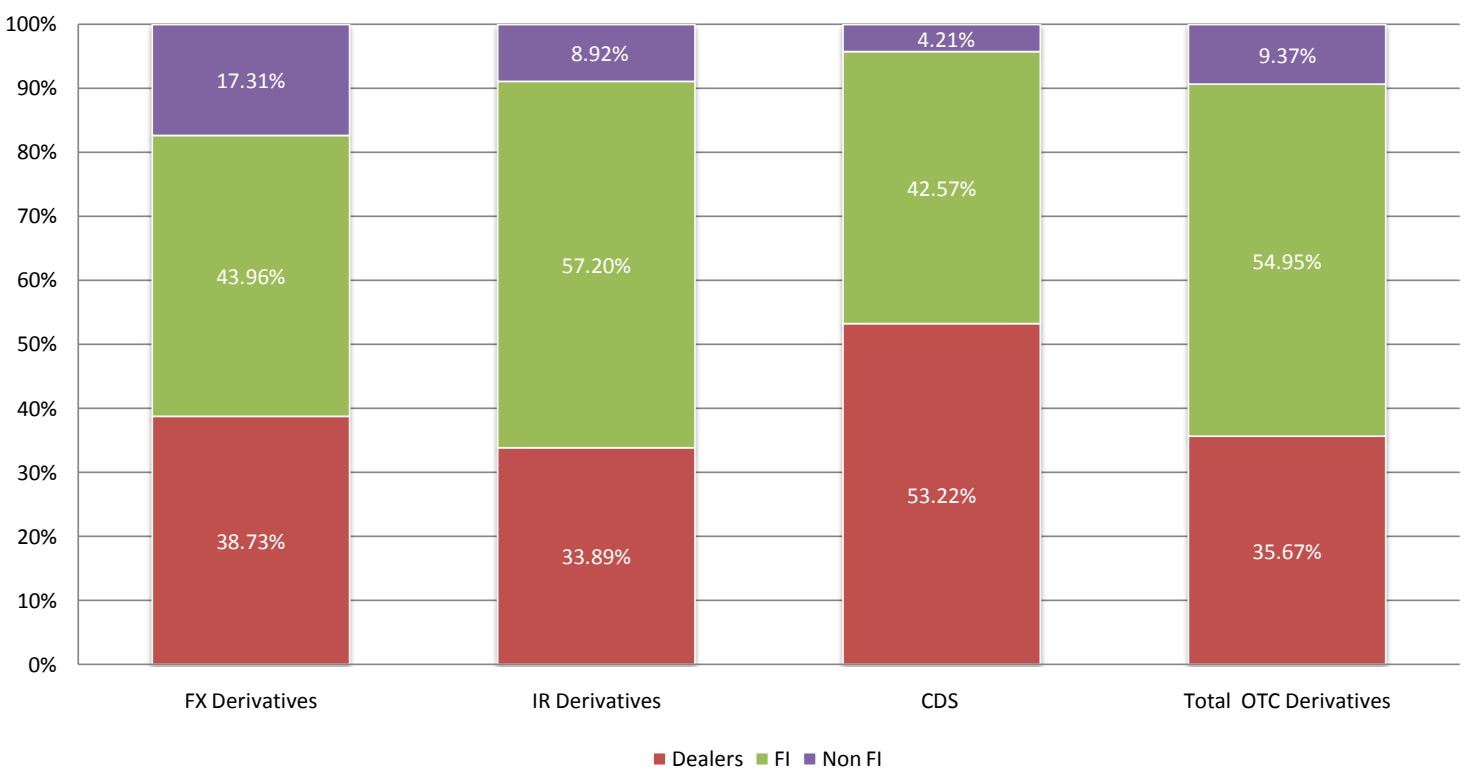

Source: BIS (2009).

\footnotetext{
${ }^{21}$ ICAP - TriOptima data show that the gross notional value of OTC derivatives terminated between 2007 and 2009 is $\$ 54.7$ trillion for credit derivatives and \$47 trillion for products based on interest rates. In 2009 alone, triReduce has terminated $\$ 14.5$ trillion of credit derivatives and $\$ 25.8$ trillion of rates derivatives.

${ }^{22}$ See Simon Grensted's presentation (LCH.Clearnet) at ECMI seminar, "OTC Derivatives: Catching the train to centralization", $\quad 20 \quad$ November 2009 (http://www.eurocapitalmarkets.org/system/files/ECMI_Grensted_20nov09.pdf).
} 
Nearly two-thirds of OTC derivatives have a simple contract structure with individual customisation (Nystedt, 2004). Several risks are embedded in these transactions, with potentially disruptive systemic effects due to the interconnectedness of global financial markets and linkages between counterparties (so-called 'cascade effects'). However, these financial instruments allow the shifting of risks to entities that are better equipped to bear them.

We identify several economic risks and group them into two categories: idiosyncratic and external (see table below). ${ }^{23}$ Idiosyncratic risks derive from the nature of counterparties and the specific market risk of the underlying variable or financial instrument. All other risks should be seen as external to the 'pure' transaction, even though they may affect the transaction itself.

Table 2. Economic risks

\begin{tabular}{ll|ll}
\hline \multicolumn{1}{c|}{ Idiosyncratic risks } & \multicolumn{1}{c}{ External risks } \\
\hline 1. Size and complexity of exposures & 1. & Collateralisation and transparency of \\
2. & Counterparty credit risk & transactions and market infrastructures \\
3. & Market risks & 2. & Market liquidity \\
4. Long-term funding & 3. & Legal risks \\
& 4. & Network externalities and cascade effects \\
& 5. & Number of dealers and/or CCPs \\
& 6. & Clearing and settlement risks (confirmation \\
& & backlogs, etc.) \\
\hline
\end{tabular}

On the one side, the group of idiosyncratic risks includes those fuelled by the characteristics of the transaction and market participants, as well as their market risk.

- Lack of transparency on the overall transaction or on real counterparty's financial exposures (not only to derivatives) may increase the overall risk, as strategic decisions in the company's business activity may affect the resiliency of the derivative transaction (i.e. counterparty credit risk). More attention, then, should be given to the use of derivatives instruments to speculate on specific firms through inside information (IOSCO, 2009).

- The derivative transaction typically involves a long-term contractual relationship where the buyer's benefits (which represent liability for the derivative's seller) are immediate, while the remuneration for the seller of the product is often diluted over a long-term period. ${ }^{24}$ In the long run, the counterparty risk is higher, only because there is a higher probability that things may deteriorate for a currently healthy firm.

- Counterparty default may involve huge systemic risks, due to the high concentration of bilateral exposures (knock-on effects), information asymmetries, the cost of replacing contracts or strong bilateral interconnections (Bliss \& Papathanassiou, 2006). In addition, if a big financial institution defaults, residual derivatives transactions should be re-priced to replace current trades. As described below, this replacement cost is very high, so opportunistic behaviour should be taken into account, as the healthy party will be led to terminate in-the-money contracts and keep alive out-of-money contracts during bankruptcy procedures (Singh \& Aitken, 2009). The solvent party thus may hold up the insolvent party

\footnotetext{
${ }^{23}$ See Darby (1994) and Gonzalez-Hermosillo (1994).

${ }^{24}$ Interest rate swaps can be liquid for maturities up to 30 years; see BIS (2007).
} 
in order to obtain more favourable terms from re-pricing contracts. In this respect, the creation of efficient crisis management and default procedures is paramount.

- The mismatch between long-term funding and short-term liabilities has put derivatives dealers in a potentially risky situation when the financial crisis impacted on counterparties and indirectly on the mechanisms of margins and collateral used to seal the system from counterparty default.

- Market risks, then, include risks related to the underlying assets, such as price movements, volatility, leverage, rate of discount and liquidity (Gonzalez-Hermosillo, 1994).

On the other side, the external risks belong to the broader set of the legal framework of rules and market infrastructure. For instance, a gap in transparency rules or confirmation backlogs can create uncertainty on the exact terms of the trade and increase costs and length of litigation in case of disagreement.

- The low number of dealers and/or central counterparty (CCP) clearing, then, may affect the transaction as long as it determines a scarcely competitive and concentrated environment that impacts on the quality and resilience of the transaction.

- As these large exposures are shared between a reduced number of interdependent financial institutions, a more pervasive control of the cascade effects (or knock-on effects; ECB, 2009 ) is paramount in case the operations of one or a few players are disrupted. In effect, derivative transactions may involve systemic risks through cascade effects and network externalities - as they are backed by an intricate web of financial links and transactions which can hamper seemingly resilient transactions.

- Due to its high customisation and complexity, the market for OTC derivatives is constantly under the threat of market illiquidity or an insufficiently deep market (so-called 'replacement cost risk').

- Only a resilient market infrastructure and clearing services can deal with the mismatch between exposure and counterparty risk (European Commission, 2009b). Counterparty risk needs, therefore, to be monitored on a daily basis, through the direct management of margins requirements and if necessary requesting daily or every few days the injection of collateral. In general, the long maturity of some derivatives transactions further exposes counterparties to their own credit risk. The use of margins requirements and/or capital requirements is crucial to reduce the impact of this category of risk.

- Other external risks are related to the process of clearing, settlement and custody. Operational and legal risks (e.g. the Herstatt risk), which are typically limited, may undermine the whole transaction (see below for more details).

Finally, on the legal side, OTC derivatives transactions involve a consistent framework of legal rules. In effect, the trade is based on a contractual agreement, which requires a well-drafted text in order to avoid confirmation delays or lengthy and costly litigations, thereby reducing transaction costs (and increasing standardisation). The ISDA master agreement, novation protocol, close-out procedures and small or big bang protocols are examples of widely recognised practices and contractual models adopted by the industry to improve operations and better manage procedures in OTC transactions. In effect, legal uncertainty can undermine the transaction through 'unforeseen' margins and collateral calls that may threaten companies' balance sheets. Legal risks can hamper the orderly functioning of the markets.

Two legal instruments are widely adopted in OTC contracts to reduce transaction costs and indirectly mitigate operational, infrastructure and counterparty risk: novation and the master agreements (standard contract). Their use increases the standardisation of the transaction and 
improves the process of offsetting a specific transaction with an equivalent one (netting), as well as increasing the transparency of the real exposure of a specific counterparty. For instance, novation allows the substitution of a contract with a new one or two new contracts. ${ }^{25}$ This legal tool is used to move contracts on a Central Counterparty Clearing (CCP) for OTC or 'exchangetraded derivatives' (same legal step as explained below). Thus, through novation, the CCP or in general the new obligor can proceed with several other activities, which potentially reduce counterparty and operational risks (multilateral netting, portfolio reconciliation services, closeout procedures etc.). In effect, the new contract between the counterparty and the platform will define a new set of rules, which include CCP membership rules.

Other concerns come from the uncertainty on the legal rules applied to these contracts, which are drafted and executed in diverse jurisdictions. In specific cases of litigation or a failure of the CCP or other relevant circumstances, a uniform application of global standards across countries that clearly define the regulatory regime applied to contracts would be a welcome and efficient solution. The High Court of England and Wales recently rejected a plea from Morgan Stanley that the dispute over a derivatives transaction should be heard only in the jurisdiction established in the Master Agreement (in this case, England). ${ }^{26}$ As a consequence, the counterparty sued Morgan Stanley also in its own country of origin, in this case for mis-selling practices, although the contract defines England as an established jurisdiction. This is a typical example of legal risk posed by derivatives transactions. In conclusion, a strengthened supranational supervision and global regulatory standards to be implemented by main jurisdictions should at least partially compensate the potential risk of a 'race to the bottom' between national regulators.

\section{Shedding light on the OTC derivatives' chain value: A cost- benefit analysis}

A derivatives transaction involves several steps and a long-time horizon, starting from the contractual agreement and moving to the final settlement and transaction termination (see figure below). In effect, the aim of bargaining over derivatives is often to spread out the payments to complete the transaction on a long-term basis for the purposes mentioned above, increasing particularly the clearing, settlement and counterparty risks.

Under the four categories mentioned in the figure (i.e. trading, clearing, settlement and custody), it is possible to identify six different phases:

1. Pre-trade (collection of documentation, and contractual agreement on terms)

2. Trade execution

3. Pre-clearing (verification/matching, confirmation, and novation)

4. Clearing (netting, collateral/margin management, cash flow matching, termination services)

5. Settlement (cash or physical delivery)

6. Custody (trade registration, assets segregation, and in some cases collateral management)

\footnotetext{
${ }^{25}$ For a more accurate description, see Bliss \& Papathanassiou (2006).

26 See Financial Times, "Morgan Stanley battles over China derivatives", 28 October 2009 (http://www.ft.com/cms/s/0/e222bd1a-c3f7-11de-8de6-00144feab49a.html).
} 
Figure 5. OTC derivatives transaction

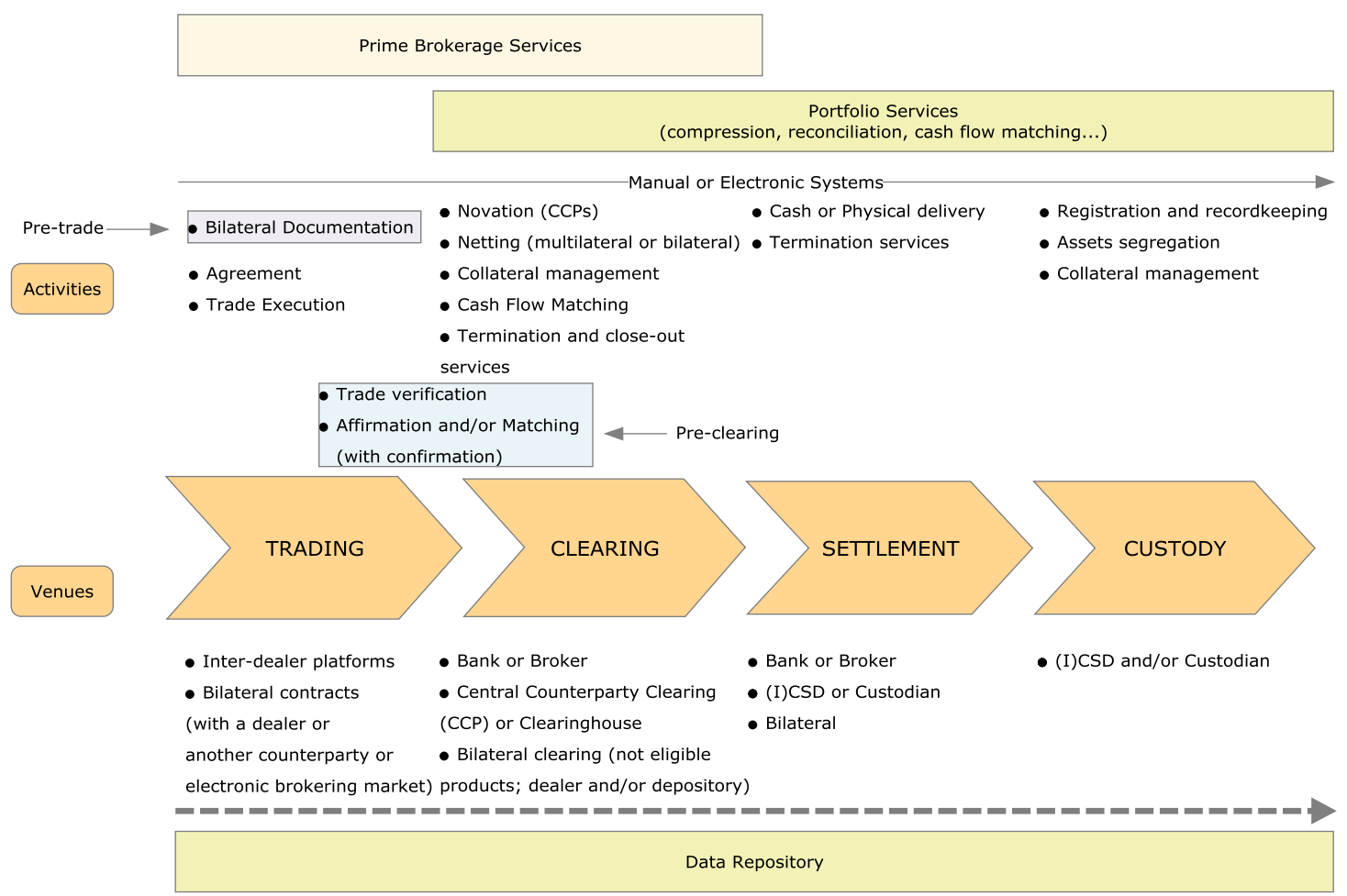

Source: Author's elaboration.

These trade-related activities, then, can be supported by complementary services, such as prime brokerage or portfolio services, or supporting institutions, e.g. a data repository (or trade information warehouse), in order to increase market transparency and resilience. For instance, prime brokerage services are offered to buy-side investors (e.g. hedge funds) in order to create a single point of access to the market for OTC derivatives (but using multiple dealers) and facilitating clearing and settlement arrangements (CPSS, 2007). The prime broker intermediates between dealer and investor, and if the transaction is accepted and confirmed, it will become counterparty to two trades, being simultaneously buyer and seller of the trade. This supplementary service aims at reducing operational costs and increasing efficiency.

\subsection{Pre-trade}

The pre-trade phase - after preliminary talks - includes the drafting and compilation of several documents such as the master agreement form, the schedule with modifications and confirmation forms with details of the trade. Then, parties collect all these documents plus, if requested, annexes with guarantees and pledge agreements. This phase thus consists of 1) designing the transactions around parties' needs and risks and 2) drafting a master agreement that minimises legal uncertainty and transaction costs. However, this phase may also take place orally. Bespoke (highly customised) transactions increase legal uncertainty and the risk of litigation, as the pre-trade is limited to preliminary talks and less to designing an efficient and accurate master agreement (it is only a verbal agreement). The risk concerns the unenforceability of bespoke transactions in specific countries. Benefits, instead, rely on the speed of execution and the possibility to handle in a highly customised way the modification of transaction details or to hedge an outstanding position in a short time frame. 


\subsection{Trade execution}

This phase is not particularly crucial in the value chain, as OTC derivatives are bilateral agreements. Thus, parties have already defined the terms and conditions when the trade needs to be executed along the details set in the agreed documentation. When the broker-dealer intermediates for other parties, the execution of the trade may take longer and be more complex. In effect, the interdealer broker may need to find one or more counterparties in order to execute the order. On the operational side, more should be done to implement straight-through processing of transactions. However, even if electronic systems and automation are more widely adopted, voice services are still in use and play an important role for customised positions, as they mix advice and a highly-customised execution service in one place in real time.

\subsection{Pre-clearing}

Once counterparties have agreed on the terms of a transaction, before clearing it, these details are captured, verified and confirmed, in order to avoid as much uncertainty as possible and thus reduce the probability of future costly disputes. In effect, unconfirmed trades (or verbally confirmed ones) reduce the likelihood of enforceability for the transaction and do not allow multilateral netting by $\mathrm{CCPs}$, increasing therefore counterparty and operational risks (ECB, 2009).

In the pre-clearing phase, the trade is verified and confirmed. This phase ensures that trading parties are in agreement about essential trade details, such as the deal price, trade date, settlement details, etc. (Oxera, 2008). It can be executed electronically or manually. The verification is actually done after the execution note, in order to verify that the details of the trade between parties are the same as the ones originally set by them. Parties thus exchange the details of the transaction, as they have been registered in their systems. Once exchanged, the confirmation of the details may follow one of two models: trade matching or trade affirmation (CPSS, 2007).

Trade matching is used when both parties prepare a confirmation form that they are going to match in order to eliminate errors and discrepancies in the details set by parties.

Trade affirmation consists of one party giving the trade details to the other, who is finally going to verify the information and proceed with the agreed trade.

Although the market has been working to reduce the number of unconfirmed outstanding trades, more should be done to push the percentage of confirmed trades within the trading day plus one business day $(\mathrm{T}+1)$ close to $100 \%,{ }^{27}$ through the support of automated and interoperable systems (CPSS-IOSCO, 2001 and ESCB-CESR, 2009). In 2009, the level of unconfirmed trades went down for all categories, except for currency derivatives, which experienced a slight increase. The monthly average of business days for outstanding confirmations is roughly 5.5-6 days for all OTC derivatives in 2009, while in 2008 it was more or less 9 days (ISDA, 2009). OTC credit derivatives have reached a high level of electronic confirmation (92\%) with almost $96 \%$ confirmed within $\mathrm{T}+2$ and $\mathrm{T}+5$. For all categories, electronic confirmation is mainly completed within $\mathrm{T}+2$ and $\mathrm{T}+5$ (except for equity derivatives), while for manual confirmations the time for completion ranges between $\mathrm{T}+6$ and $\mathrm{T}+30$ (see Table 3 below). In addition, some $0.1 \%$ to $0.7 \%$ of trades still remain unconfirmed after 180 days.

\footnotetext{
${ }^{27}$ Electronic platforms run by external players can ensure high percentages of confirmed trades. For instance, Markit Wire has succeeded in confirming 95\% of interest rate swaps on the same day, and it aims at replicating or increasing this percentage for all OTC derivatives through a joint venture with DTCC, so-called 'MarkitSERV'; see Markit, "Comments on ESCB/CESR Draft Recommendations for Central Counterparties for OTC derivatives", 16 April 2009.
} 
Table 3. Confirmation times

\begin{tabular}{|c|c|c|c|c|c|c|c|}
\hline $\begin{array}{l}\text { Confirmed trades } \\
\text { (circa \%) within }\end{array}$ & Same day & $\mathbf{T}+\mathbf{1}$ & $\mathbf{T}+2$ & $\mathbf{T}+5$ & $\begin{array}{c}T+6 \\
T+10\end{array}$ & $\begin{array}{l}T+16 \\
T+30\end{array}$ & $\begin{array}{c}\mathrm{T}+30 \text { or } \\
\text { more }\end{array}$ \\
\hline \multicolumn{8}{|l|}{ Electronic } \\
\hline Credit $(92 \%)$ & $62 \%$ & $92 \%$ & \multicolumn{2}{|c|}{$96 \%$} & $100 \%$ & - & - \\
\hline Commodities (46\%) & $60 \%$ & $97 \%$ & \multicolumn{2}{|c|}{$97 \%$} & $100 \%$ & - & - \\
\hline Currency $(51 \%)$ & $88 \%$ & $100 \%$ & \multicolumn{2}{|c|}{-} & - & - & - \\
\hline Interest rate $(48 \%)$ & $68 \%$ & $100 \%$ & \multicolumn{2}{|c|}{-} & - & - & - \\
\hline Equity $(23 \%)$ & $39 \%$ & $81 \%$ & \multicolumn{2}{|c|}{$92 \%$} & $100 \%$ & - & - \\
\hline \multicolumn{8}{|c|}{ Non-electronic or manual } \\
\hline Credit $(8 \%)$ & $15 \%$ & $50 \%$ & $60 \%$ & $95 \%$ & $97 \%$ & $99 \%$ & $100 \%$ \\
\hline Commodities $(54 \%)$ & $14 \%$ & $68 \%$ & $80 \%$ & $94 \%$ & $95 \%$ & $99 \%$ & $100 \%$ \\
\hline Currency $(49 \%)$ & $27 \%$ & $77 \%$ & $83 \%$ & $88 \%$ & $96 \%$ & $99 \%$ & $100 \%$ \\
\hline Interest rate $(52 \%)$ & $8 \%$ & $48 \%$ & $72 \%$ & $92 \%$ & $98 \%$ & $98 \%$ & $100 \%$ \\
\hline Equity (77\%) & $8 \%$ & $27 \%$ & $40 \%$ & $75 \%$ & $92 \%$ & $96 \%$ & $100 \%$ \\
\hline
\end{tabular}

Source: ISDA Operations Benchmarking Survey (2009).

Automated trade verification and confirmation, especially on the same day of the trade $(\mathrm{T}+0)$, may concretely generate direct and indirect benefits, increasing the overall efficiency of the OTC derivatives market's back office and reducing settlement failures (Oxera, 2008). More market initiatives should be encouraged in order to invest more in electronic mechanisms of verification and confirmation, as well as in a straight-through processing (STP) of transactions. The time of confirmation should not be strategically defined by the firm but it should be monitored and guided by regulators or international self-regulated bodies, through guidelines and/or incentives, in order to reduce the time of outstanding confirmation for the vast majority of these trades to $\mathrm{T}+1$. The pre-clearing phase, therefore, plays a pivotal role in the OTC derivatives market, since - without confirmation - trades may be unenforceable, with destabilising effects on the viability of one or both counterparties. For instance, the transaction (in this case, without confirmation) may not be shielded from creditors' claims in insolvency procedures. 
Box 1. The role of 'standardisation'

Standardisation is a general concept that refers to specific technical processes, economic terms and legal terms of a financial product, to allow straight-through processing (STP) of the transaction. On the one hand, OTC derivatives markets may benefit from standardised products as they permit a complete control of the chain value through electronic trading, clearing and settlement systems. On the other, not all derivative transactions can be standardised.

Three levels of standardisation can be defined (European Commission, 2009e):

1. Contract and legal standardisation,

2. Product standardisation (economic terms, e.g. payment structure and dates) and

3. Technical standardisation.

Wide adoption of uniform contracts (such as master agreements) helps to standardise the value chain, thereby allowing an STP (FSA and HM Treasury, 2009). In effect, on the one hand, common forms of master agreements reduce transaction costs and harmonise procedural details, consistently reducing expensive legal disputes and helping to smooth the legal process. On the other hand, standardised economic terms and automation promote a smooth economic and technical process of the transaction.

Nevertheless, even in highly standardised products, customisation can still be preserved for some economic terms, as long as customisation does not affect the STP of derivatives products. Most customised products need customised processing, which frequently requires non-STP procedures through manual or voice execution.

Product standardisation, therefore, assumes a uniform language for economic terms, while the individual risk profile may not be captured by a specific standardised language for economic terms (see the figure below). Pressure for standardisation should, therefore, be exerted on the determinants of the legal terms and systems automation, namely harmonisation and investments in infrastructure.

\section{Standardisation}

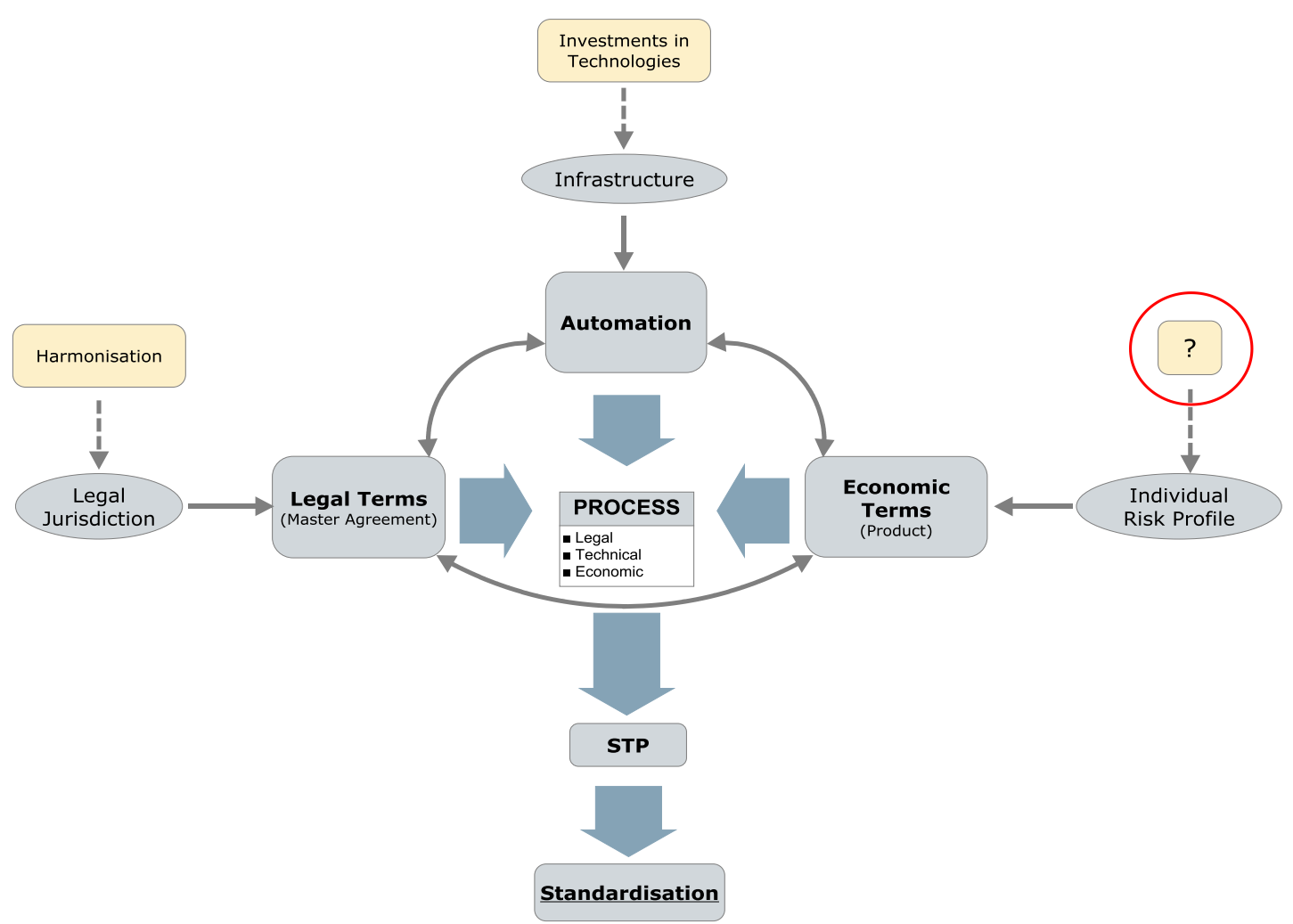

Source: Author's elaboration. 
In effect, as shown above, harmonisation of rules at global level may push contract standardisation, thereby smoothing the legal process. Contract standardisation is affected and affects automation and economic terms. On the one hand, standardisation of the master agreement affects automation through the fact that a trade frequently can only be confirmed by written consent; therefore electronic systems need to change their parameters and architecture to comply with this legal rule. The widespread use of digital signatures may drastically reduce the length of time of confirmation, promoting a smoother process. However, written consent is not legally binding in all countries, so more should be done through harmonisation to support this legal standardisation process. Nevertheless, technical standardisation will affect legal standardisation as master agreements are usually drafted in a standardised language and format, in order to enter the contract in the electronic system more quickly and easily. On the other hand, contract standardisation shapes economic terms, as parties may opt for a specific day as the starting date of the contract, if only for legal reasons.

Economic terms may then influence legal standards. For instance, novation is a widespread legal tool designed to allow multilateral netting, thereby satisfying an important economic need such as the minimisation of transaction flows. Then, economic terms shape legal terms, as they are directly correlated. The contract is designed around the economic terms of the transaction.

The same links can be identified for the technical standardisation of a derivatives transaction. Automation impacts on contract standardisation and vice versa, as already explained above. Economic terms, conversely, are influenced by technical standardisation, for example, by choosing a currency or a clearing solution that allows further automation, even though it implies in the end slightly different economic conditions. Technical standards may change as the economic terms of the transaction may be easily satisfied through automated systems or through the use of a voice or manual execution system.

Finally, legal standardisation can be promoted through globally harmonised rules. More technical standardisation can be achieved through large investments in technologies and infrastructure. Product standardisation, however, is only partially achievable, as economic needs cannot be standardised. In effect, the risk profile and appetite are linked to the individual nature of the financial institution. In any case, the interaction between legal, economic and technical standardisation of the process allows an STP and, in the end, a standardised transaction.

\section{Categories of products}

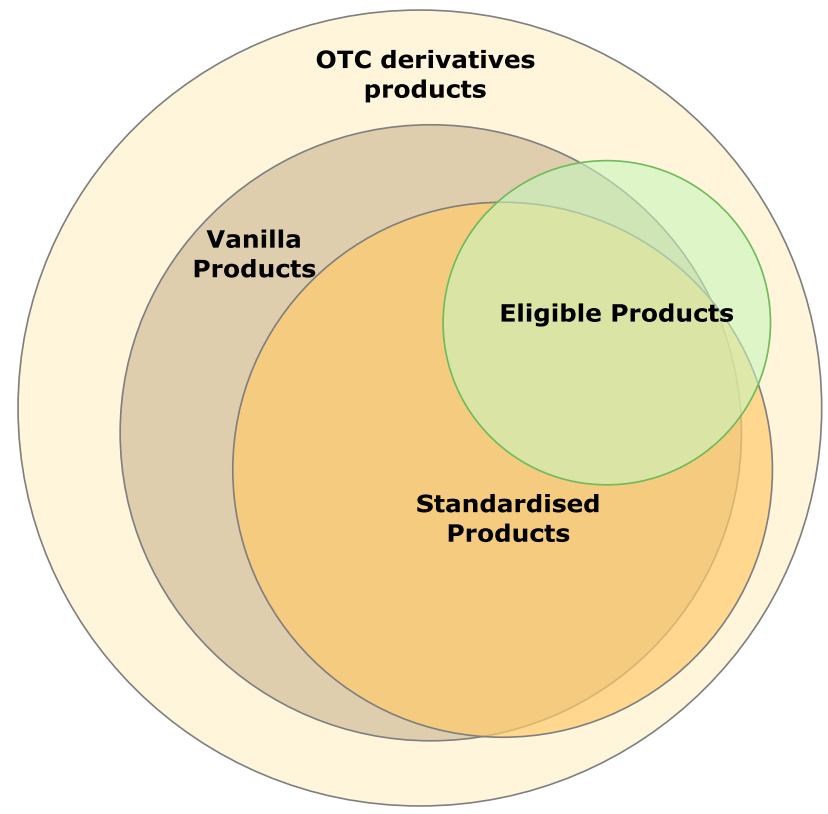

Source: Author's elaboration. 
Therefore, not all OTC derivatives can be standardised (e.g. bespoke transactions, which are indispensable tools for non-financial participants), while not all standardised products are eligible for central clearing, since further requirements must be met to access platforms, such as CCPs (see sections below). In effect, to access central clearing, clearing members need to comply with strict requirements related to the participant and not to the product, in order to keep the platform stable. In addition, there are other aspects to assess (FSA, 2009b):

1. Regular availability of prices,

2. Sufficient depth of market liquidity and

3. Absence of risks that the CCP cannot mitigate.

International currency swaps illustrate this point: they can be standardised but they are preferably cleared bilaterally, mainly for risks that the CCP cannot mitigate (e.g. settlement risks). In addition, not all standardised products are vanilla products and vice versa: vanilla characteristics mainly concern economic terms (see Figures 1 and 2), whereas standardisation requires the convergence of economic, legal and technical terms. Simplifying the transaction helps standardisation but it is not a determinant. Vanilla products, instead, can be more easily classified as eligible products for centralised clearing, as their risk lends itself to centralised management of the risk. Some $2 / 3$ of OTC derivatives are simple vanilla products (Nystedt, 2004).

\subsection{Clearing}

Once verified and confirmed, the trade reaches a crucial point in its lifecycle. Clearing has been defined as:

... the link between trading and settlement in which the obligations of each party to a transaction are finalised, that is, the process of transmitting, reconciling and confirming payment orders (or security transfer instructions) prior to settlement, possibly including the netting of instructions and the establishment of final positions for settlement (NERA, 2007, p. 9).

Clearing services, therefore, support the smooth processing of trades between execution and settlement. However, their complexity is much higher for OTC derivatives than for other securities, as clearing services must support the trade during the entire (usually long) process of a derivatives contract, from execution to final settlement (Glass, 2009). This phase includes a great variety of value-adding clearing services, in addition to the basic services performed in the pre-clearing process (Hasenpusch, 2009). These services are:

1. Netting,

2. Risk and collateral management and

3. Cash management.

Netting, in economic terms,

means the calculation of a single sum representing the potential result of the actual or notional discharge of two or more claims for payment that two persons have against each other (Crawford, 1993, p. 163).

Netting activities play a pivotal role from both a micro and macro point of view. On the one hand, from a macro point of view, they help to align the overall amounts, through bilateral or multilateral (CCP) netting, with the real exposure that counterparties may potentially suffer. On 
the other hand, this activity reduces uncertainty and supports risk and collateral management at the micro level.

In legal terms, netting has no definition, being purely an economic activity. However, the legal framework required to enforce these procedures is based on different legal concepts (Crawford, 1993). First of all, the concept of setoff, i.e. mutual debts between parties can be offset to reduce the debt to a net amount. This concept is widely recognised in the jurisprudence and global legal systems (in the UK, from the $18^{\text {th }}$ century), but the legal reasons behind this procedure are simply intended to protect one of the parties from exploitation by the other by not paying the correspondent transaction. It gives to the creditor a preference over the creditor's claims in bankruptcy procedures. ${ }^{28}$ This rule then has been largely adopted, due to the systemic importance of the derivatives market. Therefore, on one hand, netting activities need to be legally recognised across countries in order to enforce these economically valuable services, especially in case of insolvency procedures where there is a need to protect the transaction (especially cash collateral) from creditors' claims (in addition to collateral segregation) ${ }^{29}$ For instance, since 1982, the United States has had to amend its bankruptcy code (11 USCA §362; last amendment in 2005) several times in order to allow the set-off of mutual debts in this specific circumstance. ${ }^{30}$ On the other hand, however, derivatives transactions can be used to circumvent the law in order to protect the transaction from insolvency procedures. For instance, it is possible to extend a loan through a total return swap, instead of a conventional loan agreement that would put the financial institution in the queue with other creditors' claims for repayment. ${ }^{31}$

There are several techniques to provide bilateral netting services (Behof, 1993): novation, closeout, payment and by cross-product netting.

Novation is the transfer of the legal obligation linked to the OTC derivatives transaction from one of the original parties to a third party, called a transferee. The transfer is only possible through a new contract, and both original parties have to agree on it. Although novation procedures have a legal nature and need to be recognised by the legal system of the country where the transaction takes place, ${ }^{32}$ the relevant effect of this operation is largely economic. In effect, novation is the tool that allows a central counterparty clearing (CCP) netting trades on a multilateral basis.

Novation is what distinguishes a CCP from a clearinghouse. The latter, in effect, performs only bilateral netting, interposing it between two or more counterparties in order to give parties only one point of interaction, but without assuming any risk on its own in the transaction (it does not bear market risk as a CCP potentially does; see Dale, 1998). The alternatives to novation can be open offers or guarantee schemes (Bliss \& Papathanassiou, 2006). The former consists of an offer for eligible securities made by the CCP to eligible clearing members in order to attract a

\footnotetext{
${ }^{28}$ See Re/Max Metro-City Realty Ltd. v. Baker (Trustee of) (1993), 16 C.B.R. (3d) 308 (Ont. Ct. (Gen Div.)) in Canada.

${ }^{29}$ A famous US case law, Beverly Hills Sav. v. Renault Acceptance B.V. No. C-549-684 (Cal. Super. Ct. May 30, 1985), impeded Renault from terminating a swap contract and selling a bankrupt party's collateral to satisfy debt.

${ }^{30}$ A specific section (\$560) was added to the bankruptcy code in 1990 and amended in 2005; see Pub.L. 101-311, Title I, § 106(a), June 25, 1990, 104 Stat. 268, and amended Pub.L. 109-8, Title IX, § 907(j), (o)(10), Apr. 20, 2005, 119 Stat. 178, 182.

${ }^{31}$ See The Economist, "Over the counter, out of sight", 12 November 2009.

32 In addition, there is a protocol made by ISDA in order to standardise this operation and avoid unconfirmed trades. The obligation to receive the written consent to the novation from the remaining party is the main reason why a big part of trades remain unconfirmed.
} 
defined number of transactions on the CCP (after matching trades details). Once terms have been accepted, parties will terminate the contracts and a new contract with the CCP will be drawn up. It is usually used to deal with trading facilities as exchange central order books or alternative trading platforms. The latter, instead, implies no direct exposure to the defaulting party, but guarantees directly act on the contracts in order to avoid knock-on effects in case the market participant fails. Multilateral netting occurs when the CCP proceeds with the set-off of all the positions with its counterparties (after novation) in order to reduce the outstanding residuals to one single debt/credit flow between the transferor and the CCP (transferee). The value of multilateral netting increases with the number of transactions in the market, as the benefit of reducing the complexity of the huge web of bilateral exposures increases (Hasenpusch, 2009).

Cancellation and close-out netting are procedures that terminate the derivative transaction when a credit event occurs - with a pre-defined payment (non-executory contracts) or markedto-market netting of reciprocal payments (executory contracts; see Bliss \& Kaufman, 2005). For instance, it may happen when one of the two parties defaults or receives a downgrade. The termination, therefore, protects against cherry-picking by counterparties, for example, in insolvency procedures. However, the value of the transaction or of the final payment is usually determined by the solvent counterparty. This increases the risk of future litigation, even though termination avoids unexpected consequences that can undermine the economic viability of solvent financial institutions (knock-on effects). It is crucial, therefore, that counterparties agree on the methodology to be adopted if a close-out event occurs. Without close-out, however, the risk of being 'locked up' in the OTC derivatives transaction is high, as long as the market moves against the solvent party. In this case, the viability of the solvent counterparty may potentially be under threat. If the market was already against the solvent party, a sudden closeout and the request to the solvent party to inject more liquidity may affect its financial stability. The crucial role of close-out, as a netting and terminating procedure, is confirmed by its widespread use in the OTC derivatives market. Currently, circa $85 \%$ of master agreements contain a close-out procedure. ${ }^{33}$ If recognised in the legal jurisdiction, it is the tool that allows an efficient use of collateralisation measures (transactions can account on a net basis). There are also alternatives to close-out, such as selling books of OTC derivatives to a solvent counterparty when one is available or receiving guarantees from the insolvency administrator, which may have no legal basis and give parties the wrong incentives and scarce monitoring powers (moral hazard).

Payment and cross-product netting are largely used in bilateral netting of OTC derivatives transactions. The former method is an exchange of payments based on an unwritten agreement, but this sometimes raises legal complications. The latter method tries to net across products (i.e. exposures to different products). In this case, legal (and economic) complications may emerge from the potential lack of homogeneity between the object of the two obligations and from problems in assessing the right amount to net, with the risk of expensive and long litigation.

The process of associating positions, managed by clearing players, with a specific inherent risk is called risk management (Hasenpusch, 2009). Procedures of risk management should be adequately supported by appropriate safeguard provisions and tools. We can identify a list of safeguards that may be adopted by a CCP or bilateral clearers to manage specific risks (see table below).

\footnotetext{
${ }^{33}$ Data provided by Richard Metcalfe (ISDA) at ECMI seminar, "OTC Derivatives: Catching the train to centralization", $\quad 20 \quad$ November 2009 (http://www.eurocapitalmarkets.org/system/files/ECMI_Grensted_20nov09.pdf).
} 
Table 4. Safeguards for managing risk

\begin{tabular}{|c|c|}
\hline CCP & Bilateral \\
\hline 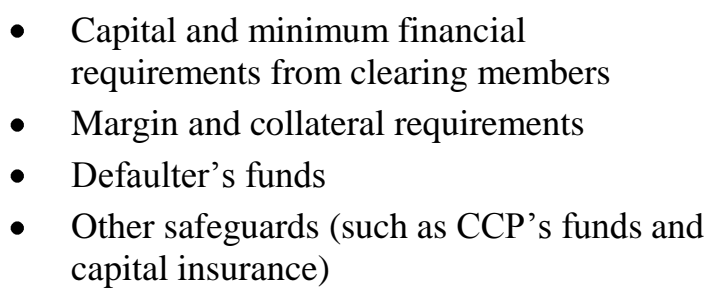 & $\begin{array}{ll}\text { - } & \text { Minimum financial requirements } \\
\text { - } & \text { Other requirements (e.g. independent } \\
& \text { amounts and capital charges) }\end{array}$ \\
\hline
\end{tabular}

Margin and collateral requirements consist of a set of resources used to mitigate credit risk in a financial transaction. These tools entail several procedures, such as periodically measuring the value of the collateral that should be provided for the derivative transaction and determining final haircuts (Bliss \& Steigerwald, 2006). For instance, CCPs usually adopt initial and variation margins. The former is used as the primary protection against a transaction's failure and immediate risk of non-performance. The latter, instead, can periodically change (e.g. on a daily basis) in order to link credit risk to the current market value of the transaction. This updating, for obvious reasons of costs, is not continuous, but is usually done at agreed intervals of time. CCPs perform this activity through one or more margin calls (or release if collateral is in excess) during the trading day. In addition, as described below, CCPs also provide other safeguards such as default funds and capital insurance.

The amount of collateral used for bilateral OTC derivatives transactions has been constantly growing in the last three years. In 2009, in particular, it almost doubled, peaking at $\$ 4$ trillion, while $66 \%$ of credit exposures to OTC derivatives are fully collateralised. Currently, $78 \%$ of all OTC derivatives transactions are covered by collateral arrangements (ISDA, 2010b), even though there is no legal obligation to provide credit risk mitigation measures (such as collateralisation). At present, $83.5 \%$ of collateral is composed of cash and $16.5 \%$ of pledged securities (9\% government securities and $7.5 \%$ other securities; see ISDA Margin Survey, 2009). However, on one hand, if cash collateral permits the partial hedging of credit risk with the most liquid asset, on the other, it gives more uncertainty because, once delivered to the counterparty, its traceability may become an issue in case of bankruptcy. Pledged securities, instead, are easily retrievable in default procedures (Behof, 1993). Then, an insufficiently meditated increase of margin requirements can reverse the current normal trend or activity of the firm, which may be called upon to inject high amounts of collateral without holding or having the possibility to access it on short notice. In effect, efficient collateral agreements should require daily calculations and calling/returning of collateral. Collateral arrangements therefore play a crucial role in bilateral transactions. However, there is no legal obligation by the collateral taker to segregate the amount received - even if it is in excess to the amount required as additional collateral (independent amount) - and the collateral provider does not have any proprietary interest in the collateral itself, while the collateral taker receives full legal and beneficial ownership in the collateral (ISDA, 2010b). This situation may create problems on the legal protection of these assets, especially in case of bankruptcy (e.g. Lehman Brothers). Asset segregation through third parties should be foreseen by legal jurisdictions for initial margins and independent amounts (over-collateralisation), in order to protect the assets from external risks and to preserve the financial viability of the involved parties (also minimising the number of litigations). Asset segregation can be done in several ways, but it will be necessary to update ISDA Credit Support Annexes as well as the legal opinions endorsed by relevant jurisdictions (ISDA, 2010a). Variation margins, instead, may need flexibility to deal with daily calculations and calls/returns and they should not be eventually segregated. In addition, independent amounts should be voluntarily or mandatorily provided by parties to increase over- 
collateralisation of transactions, as the default fund available in a CCP environment. The provision of independent amounts is foreseen by bilateral agreements. There is no legal obligation to provide such resources to mitigate credit risk.

In conclusion, we have identified an array of services used to manage cash resources for netting, collateral and other purposes that are involved in clearing OTC derivatives transactions (e.g. cash payments). These services play a crucial role in the economics of a derivatives transaction, as they are indispensable tools for handling enormous flow of transactions and meeting customised risk needs.

\subsection{Central counterparty clearing: Benefits and risks for the OTC derivatives market}

A central counterparty clearing $(\mathrm{CCP})$ "interposes itself between counterparties to a trade, becoming the buyer to every seller and the seller to every buyer. ... the credit risk of the CCP is substituted with the credit risk of the other participants" (CPSS-IOSCO, 2004, p. 6; ESCBCESR, 2009, p. 33). The CCP's role consists of managing counterparty risks in derivatives transactions, which may be seen as market risk once clearing services have shaped and added the transaction in the huge basket managed by a CCP. In fact, clearing services transform credit risk into market risk and CCPs manage it through the straight-through processing (STP) of transaction (mainly default management, price transparency and liquidity).

Figure 6. Bilateral-Clearinghouse-CCP Clearing

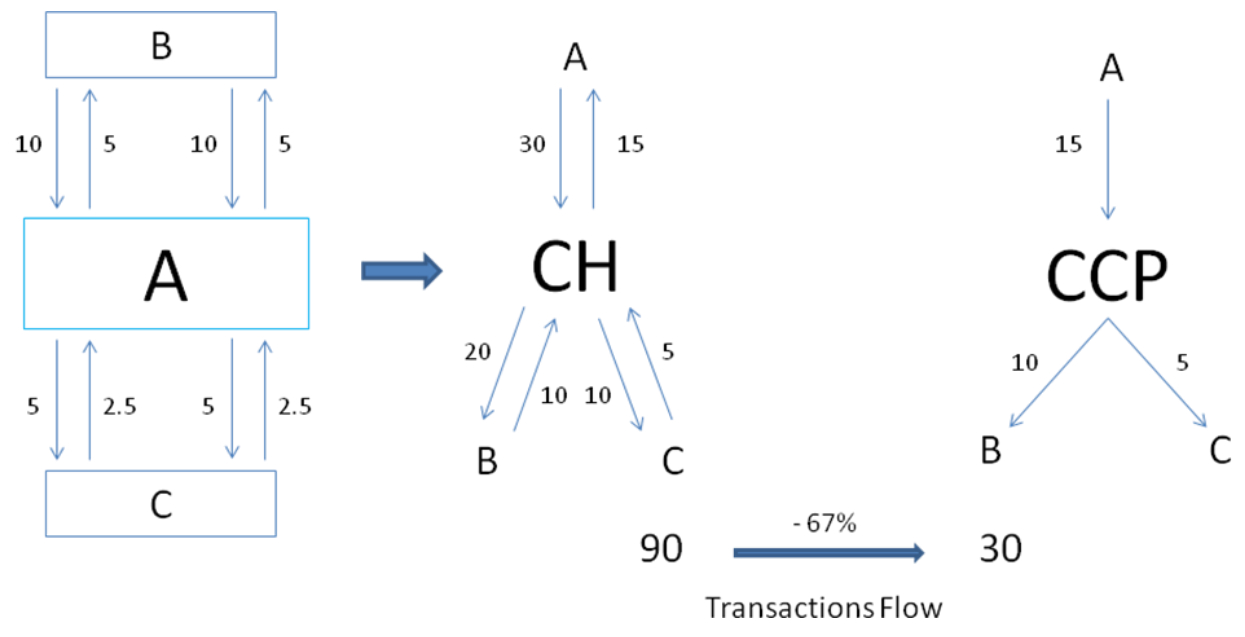

Source: Author.

As shown in the figure above, CCPs differ from clearinghouses, in that they assume some transaction risk in their operations (and indirectly move it on to clearing members). In effect, novating every eligible transaction involves risks due to unconfirmed trades and backlogs. Novation, however, allows consistent reduction of transaction flows and payments, while both clearinghouses and CCPs provide a great advantage in comparison to bilateral transactions, as they become the only transaction point for their own members. In this way, when the number of transactions is really high, counterparties will reduce transaction costs using platforms as CCPs to net or to deal with other clearing services, such as single transaction points, instead of dealing with many counterparties. The CCP allows centralisation of the credit risk, which will be borne by the whole network around the CCP. Therefore, the more liquid the market, the more efficient it is to have centralised network solutions, such as a CCP or a clearinghouse. Furthermore, although important infrastructure in the access for competitors in the upstream (execution) and 
downstream market (settlement), a CCP cannot be considered an essential facility, as it is replicable by other financial firms (Whish, 2005).

CCPs bring, under specific assumptions (e.g. market liquidity), many benefits:

- Multilateral netting. In effect, novation allows CCPs simultaneous powerful netting of positions between many counterparties; this reduces operational and counterparty risks on the single clearing member, but at the same time this activity makes it easier to exit the market and close positions if a firm no longer desires to take a position through derivative transactions; finally, it reduces procyclicality, as multilateral netting implies less use of collateral and reduced risks of sudden injections of collateral due to rating downgrades.

- Counterparty risk management. CCPs usually offer best practices for collateral and margin requirements with daily calls and initial margins, plus other safeguards, e.g. default fund; however, CCPs do not eliminate counterparty risk but they just mitigate and redistribute it in a more efficient way, through the mechanisms of safeguard and mutualisation of losses.

- Reduced spill-over effects. CCPs set crisis management rules and specific procedures in case of default of a clearing member, which should be regularly tested (ESCB-CESR, 2009). As a last resort, after taken into account all the defaulter's resources, CCPs may mutualise residual losses between all clearing members; these mechanisms drastically reduce negative externalities and absorb market risk (Cecchetti et al., 2009). In this regard, we can define CCPs as network infrastructures, where the resiliency of the infrastructure is defined by the number and the quality of clearing members.

- Liquidity resilience. Other positive aspect of the platform is the control of replacement costs, as the CCP will access a broad network of participants (CPSS-IOSCO, 2004). A smoother clearing process, through $\mathrm{CCP}$ as the only access point, will enhance market liquidity, in particular for highly standardised products that are eligible to be centrally cleared).

- Economies of scale. CCPs, as network platforms, can achieve significant scale, drastically reducing clearing services fees and, at the same time, transaction costs for clearing members.

- Transparency and information asymmetries. CCPs implicitly reduce information asymmetries that affect OTC derivatives transactions, through strict requirements to clearing members and clearing processes. They may also potentially be a source of transparency for financial markets, especially for regulators, since they store all trade details of centrally-cleared transactions; however, CCPs' role consist of providing clearing services with specific safeguards in order to mitigate systemic risks; their core services may not be able to offer qualitative transparency services across derivative products centrally and bilaterally cleared, as a trade repository may actually do, giving an overall aggregate picture of the market.

Therefore, CCPs show a valid system of safeguards through: access restriction for membership through capital requirements to participate in the platform; initial and variation margin, and collateral requirements in order to mitigate (through homogenisation of) counterparty risk as it changes with market conditions; assets segregation, in order to protect collateral from thirdparties' claims but also to limit losses for CCPs and their clearing members; creation of a default fund, composed of resources provided by the financial firm running the platform and by clearing members as well; and mutualisation of losses through guarantee funds or back-up insurance arrangements made by clearing members. 
However, derivative contracts efficiently cleared through CCPs may incur risks due to this centralised process. Risks and costs of centralised clearing should be carefully evaluated, as these network infrastructures may be a source of financial instability once they become 'too big to fail'. The following risks have been identified:

- Switching cost risk. The creation of platforms, such as CCPs, involve high fixed costs and initial investments for financial firms that want to create this infrastructure. These high fixed costs will make it more expensive and complex for the market to reverse this decision in the future; the cost of access and initial requirements to access the CCP may not allow clearing members to switch between CCPs, which may in the end fail to reach their critical mass of clearing members and transactions, thereby undermining the whole mechanism of risk and crisis management performed by a CCP.

- Cross-border legal risks. Since the OTC derivatives market works globally, the legal risks in cross-border transactions increase the number of unconfirmed or incomplete trades and the need for globally harmonised rules, such as novation and close-out (ESCB-CESR, 2009). Different legal rules for segregation may involve relevant legal risks in cross-border transactions.

- Concentration and operational risks. The concentration of millions of transactions on a few platforms will firstly increase operational risks and replacement cost exposures (Dale, 1998; Culp, 2009), as the CCP will have to simultaneously process (verification, confirmation, etc.) thousands of trades, plus ensuring that the novation of contracts will not create unforeseen operational risks, as it is main source of unconfirmed trades, especially on crossborder transactions (the market for OTC derivatives is global). For instance, in cash equity markets, CCPs rely on trades being verified and confirmed on the same day in order to be included in overnight netting and novation processes; secondly, the concentration of counterparty risks on the same platform will increase the interconnection between clearing members, thereby enhancing the 'essential' aspect of infrastructures; finally, the absence of much infrastructure will enhance the importance of market liquidity for the viability of the platform and indirectly of the whole market. This situation creates incentives for moral hazard, as these institutions will be too big and interconnected to fail (Bliss \& Papathanassiou, 2006).

- Market liquidity risk. CCPs should always ensure that there is enough market liquidity to allow the platform to work, for instance, increasing the fungibility of contracts through stricter requirements for eligibility, as long as this definition will allow reaching the optimal capacity.

- Interoperability risk. A minimum level of interoperability between CCPs is essential in the process of centralisation of clearing, as it allows some competition in servicing costs, spreading best practices in risk and crises management, and improving market entry and default procedures, through specific arrangements between them. However, interoperability involves a double risk: the failure of a CCP may hamper the economic viability of linked CCPs with disruptive effects, and moral hazard may affect the strategies of CCPs, as interconnection will make them too strong to let them fail (CESR \& ECB, 2009). In addition, information asymmetries may discourage the efficient level of interoperability, as a CCP may not have enough information or have enough incentives to provide information over eligibility, margin and other safeguards of the linked platform; competition problems may also arise as only a few entities will control the entire market, so it is paramount to ensure smooth market entry and exit through interoperability.

- Adverse selection risk. Mechanisms of adverse selection may arise due to the definition of eligibility and initial requirements for clearing memberships. In effect, bad quality users 
will not have the incentive to disclose information that could increase requirements to access the CCP and move on more costly bilateral trading; in this way, CCPs may maintain their eligibility requirements at an excessively high level, forcing good quality users to gradually reduce their exposure to OTC derivatives to an inefficient level or make use of alternative, probably riskier, products. This mechanism has spiralling effects on the quality of users accessing the CCPs, thereby undermining the stability of the market itself.

- Moral hazard risk. Conversely, if the firm running a CCP is not deeply involved in providing financial support to the platform, moral hazard risks may arise in the process of selection of clearing members and eligible products, as the value of the platform is mainly linked to the number of clearing institutions and products eligible to be efficiently cleared.

- Governance and access risk. Governance of CCPs should be shielded from conflicts of interest with clearing institutions as long as regulatory or policy actions do not affect the business and the delicate mechanisms of incentives that bring together all clearing members on the same platform (see section 8). In addition, non-discriminatory rules should apply for access to the platform (ESCB \& CESR, 2009) in the upstream (trading venues) and downstream (clearing members) side of the market. Access by trading venues to the CCP, technological differences, discriminatory cost practices and work flow management can be areas for discriminatory practices.

- Supervisory risk. The supervision of CCPs that are based in different countries and subject to different legal systems may imply cross-border risks in supervising and verifying that best practices and standards are applied across interlinked and/or isolated CCPs.

A minimum level of interoperability for transactions across CCPs with open and nondiscriminatory access to these platforms should be a priority, considering the above-mentioned risks.

Nevertheless, as long as the market is liquid and supervision is strong, the long-standing dispute over the necessity of one or more CCPs becomes moot because the number of competing CCPs is typically decided by the market. In effect, when liquidity is low, the reduced netting opportunities will increase collateral requirements and exposure to counterparty credit risk with more than one CCP (Duffie \& Zhu, 2009). Regional CCPs, however, are not indispensable, even if regulators opt for strengthening the 'essentiality' of CCPs in OTC derivatives clearing, because central banks should only intervene in their currency-denominated derivative transaction, and not on the basis that the CCP, which processes the transaction, is a legal entity based in the US rather than Europe. This was clearly done for the banking system during the current financial crisis. Thus, it is crucial to ensure access to central banks' liquidity, in order to keep the market liquid in case of failure of one or more CCPs (Cecchetti et al., 2009).

In terms of supervision, it is important that these new entities will be supervised with stronger international coordination, especially if the main currency traded is that of a country other than the one in which the entity is based. In addition, a still rarely discussed problem is the nondealer access to the platform. Non-dealer participants may participate in centrally-cleared derivatives transactions that are not at all related to their core business, so they should be only partially involved in the mutualised mechanisms of the infrastructure. Therefore, a sort of indirect membership may be granted to these non-professional participants, in order to limit their stake of the risk (FSA, 2009b).

In terms of legal aspects, centralised solutions should be supported by carefully drafted contracts, in order to avoid constant involvement in costly litigation across several countries over legal terms. Legal risks with customised derivatives transactions may hamper the proper function and activity of a CCP. The currently adopted solution based on the country of origin of 
the CCP seems sufficient to deal with global markets as it does not sacrifice a party's legal right to sue another party in case of violations of the law or the contract. However, it raises concerns about a potential 'race to the bottom', which regulators would pursue in order to attract more CCPs and so more business. In effect, incentives for regulators to standardise national rules to global standards are extremely low. Therefore, a strengthened supranational supervision and global mandatory standards for CCPs should at least partially compensate for this potential risk of a 'race to the bottom' between national regulators.

Finally, we can conclude that central clearing through CCPs is not a better solution than bilateral clearing in every circumstance. There are pros and cons that should be carefully taken into account (such as moral hazard and adverse selection). Central clearing would probably be a better solution for some standardised classes of products, with high volumes of trades and numerous counterparties. Bilateral clearing, instead, will continue and should be allowed to operate under the same (or almost the same) requirements expected of CCPs because, as explained above, several aspects may impede OTC derivatives to clear on CCPs without necessarily increasing risks and inefficiencies. If derivatives contracts do not meet such efficiency conditions or show greater signs of the mentioned risks if cleared on CCPs, there is no evidence and economic justification that bilaterally cleared products should be subject to stricter requirements than those applied to CCPs. Any attempt to discourage bilateral clearing for every OTC derivatives transaction will create serious risks of instability, as well as fewer opportunities, in specific cases, to customise risks in the most efficient way. Unquestionably, more should be done in terms of collateral requirements, use of best practices to reduce counterparty risk and better trading and settlement infrastructures, and less on capital charges for non-centrally cleared transactions. Any attempt to increase the resilience of OTC derivatives markets without a proper assessment of the actual consequences may create instability or affect the efficient market functioning in both the short and long run.

\subsection{Other complementary services}

The value chain of OTC derivatives transactions is supported by many complementary services, such as bookkeeping, accounting and regulatory information provision (Hasenpusch, 2009). Two services in particular, however, play an important role in propping up the efficiency of a derivative's value chain and reducing the impact of exposures.

Firstly, portfolio reconciliation services entail resolution mechanisms to solve disputes over the management of collateral and independent amounts (ISDA, 2010b). Failed reconciliations are very common in OTC derivatives and they increase costs and time of the transaction, sometimes due to trivial mistakes. Therefore, these services match collateral portfolios of counterparties and evaluate differences in order to avoid or prevent potential disagreements (ECB, 2009). The majority of reconciliation services are provided on a daily basis, while a relevant number of trades are reconciled on ad hoc basis or in response to disputes (ISDA Margin Survey 2010 Preliminary Results, in ISDA, 2010b).

Secondly, portfolio compression services are widely adopted because they reduce the size of the exposure to OTC derivatives. In effect, the portfolio may be inflated by potentially offset trades and redundancies, which these services can terminate. This compression may reduce the collateral and capital requirements burdening the company for the use of OTC derivatives. So they can be considered as 'Pareto-efficient' services, increasing the utility of the transaction for both parties without affecting the utility of anyone else. For instance, since January 2008, the notional value of CDS positions has decreased from over $\$ 60$ trillion to below $\$ 30$ trillion, mainly through the widespread use of portfolio compression services. (Duffie et al., 2010).

Both reconciliation and compression will be even more widely adopted in the coming months, since new legislative proposals will be pushing towards more capital and collateral requirements 
for derivatives transactions. These services are of great support, especially for bilaterally cleared transactions.

Finally, trades, as described above, may be terminated before the maturity date if agreed by parties. Therefore, there are specific so-called 'termination services' that can support the agreed terms of earlier termination.

\section{Box 2. What is the role of trade repositories? Competition $v$. centralisation}

A trade repository (or central data repository or swap repository) is an entity that collects data on contracts traded in various segments of the OTC derivatives markets, centrally or non-centrally cleared. For operational reasons, its introduction in OTC derivatives markets has been pushed for, as individually negotiated transactions could be easily tracked after confirmation, especially on large books of bilateral contracts. In effect, trade repositories store contracts and all the details of the transactions. In this way, for instance, a data repository can facilitate close-out procedures, but at the same time it can reduce the negative impact of these procedures for the viability of solvent institutions, as exposures can be controlled in real time. The qualitative service eventually performed by these entities may also support other less-invasive services performed by third parties (such as portfolio compression and reconciliation services).

Trade repositories are not an alternative to CCPs. However, a trade repository provides some services partially replicated by CCPs, such as storing and processing information in order to provide an efficient credit event management, a rapid and accurate payment process to calculate settlement amounts and multilateral net settlement by third parties. Finally, this information service makes the bilateral margin processing more efficient.

There are differences that may justify the creation of a trade data repository, even if ideally CCPs were largely diffused in the market. A trade repository collects contracts for all OTC derivatives transactions, especially if bilaterally cleared, and provides a level of granularity that is not requested of centrally-cleared products (in particular if they adopt omnibus accounts). Since bilateral transactions will still be a relevant part of the market and granular information will be even more frequently requested, the presence of a trade repository would still be needed. Another important reason to use a trade repository, which represents its aim, is the ability to process a huge amount of information in order to increase transparency on the real exposures of financial and non-financial institutions. Their existence is justified by the provision of services that would assure the accuracy of the information. This will indirectly help to bring systemic risk under control through an accurate picture of the market, whether or not the derivative transaction is centrally cleared. A data repository should be able to produce a reliable picture of a specific market and its methods of execution or clearing. For instance, the DTCC trade warehouse, which now also provides matching and confirmation services with MarkitSERV (Derv/SERV), gave strong support to efforts to assess the real exposure of Lehman Brothers to credit derivatives, as over $90 \%$ of CDS contracts are stored on this platform.

In this regard, many observers have expressed doubt over the wisdom of creating more than one trade repository. The number of trade repositories should not be a problem, however, as long as the market is helped to find its own equilibrium. Most notably, regulators and market participants should push forcefully for the standardisation of the format in which data are shared and diffused to trade repositories and to the market. Contracts details, which are the product subject to competition, should be drafted and consequently shared with a single format, in order to make 
the product as homogeneous as possible and to promote competition between trade repositories on providing more qualitative additional services and thus transparency. In addition, every transaction should be linked to a universal code to be recognised and to avoid double counting and misreporting. In effect, there are potential risks that incumbents may try to impose a format as a way to segment the market and make it more profitable. This would create serious risks for market transparency and indirectly for the entire market for OTC derivatives. It is in the financial institution's interest that the quality of the services provided by a trade repository remains valuable, as it will use those services to reduce its exposure and collateral as much as possible and to make the transaction faster and safer.

In conclusion, some regulators argued that at least one data repository should be created in every region, in order to avoid uncontrolled situations and increase market transparency. Both motivations are potentially wrong and inconsistent as, even if you have regional repositories, there will still be a need for guidelines and requirements to provide access to these services to regulators. From a legal point of view, where contracts are physically or electronically located does not affect the transaction nor its legal validity. Then, there are no relevant commercial needs or cost savings for European institutions with the registration of the transaction in Europe instead of the US. Some issues may arise concerning the access that regulators should equally have to these warehouses of data. Their creation, therefore, should be allowed as long as these entities give financial regulators across the world full access to their registries. For instance, the DTCC data warehouse gave full access to regulators and the fact that it is based in the US did not affect the process of registration of CDSs that were not executed, cleared or settled on US platforms. In effect, more than $90 \%$ of credit default swap transactions are stored in the DTCC data warehouse. The risk of imposing the creation of regional facilities or the registration on regional facilities may increase transaction costs and reduce the global competition, which have done a lot so far to improve business models and the portfolio of services around OTC derivative transactions.

\subsection{Settlement and custody}

Settlement services consist of a range of services for cash or physical delivery of a derivatives transaction or its underlying asset. They may include termination services to support the early settlement of the transaction, such as close-out procedures. The role of settlement services is relevant, as they add further risks (not only operational ones) to the value chain if the lapse of time between trade execution and settlement is particularly high. ${ }^{34}$ It should not be more than $\mathrm{T}+3$, following European standards and global recommendations (CPSS \& IOSCO, 2004 and ESCB \& CESR, 2009). The amount and type of services strictly depends on the type of products. Most transactions are preferably settled in central bank money through specialised banks, TARGET2 (for euro-denominated transactions) or Fedwire (for dollar-denominated transactions). Cash or physical assets will be delivered in existing central securities depositories (CSDs) (see ECB, 2009), preferably after being immobilised or dematerialised, in order to minimise other relevant risks (ESCB \& CESR, 2009). However, credit default swaps and foreign exchange derivatives are mainly settled through CLS Bank, an entity regulated and supervised by the Federal Reserve, ${ }^{35}$ while there are still transactions settled through bilateral

\footnotetext{
${ }^{34}$ This risk is called Herstatt risk (or principal risk), from the name of the German bank that in a crossborder foreign currency transaction in 1974 failed to deliver the agreed amount in USD after it had already received the German currency payment, because between the two payments (in the same day) the German regulator withdrew its license and the bank blocked its activities and all payments.

${ }^{35}$ For more information on CLS Bank, see http://www.cls-group.com.
} 
netting agreements. Furthermore, clearinghouses and CCPs may also establish arrangements to become settlement institutions for centralised trades, as well as providing limited guarantees to the trades.

The last ring of the chain is represented by custody services, which include registration and record-keeping of transactions, assets segregation and in specific cases collateral management. These services, for cash products, are usually performed by CSDs and custodian banks. This phase may be of crucial importance from two points of view: transparency and legal risks. On transparency, an accurate recordkeeping of trade details is essential to control risk exposures to OTC derivatives. On legal risks, assets segregation is a practice that protects collateral and other assets involved in the transactions from creditors' claims in bankruptcy procedures, rather than other legal claims. Protection through segregation may be efficiently achieved if a customer's assets are kept safe through apposite accounts (ESCB \& CESR, 2009). Improper provision of these services may affect the entire transaction and indirectly hamper the viability of involved counterparties.

\section{The OTC derivatives market and the financial crisis}

Although the OTC derivatives market did not trigger the current financial crisis, the worsening of the economic outlook and the deterioration of credit exposures ${ }^{36}$ have had an impact on margins and collateral requirements, necessitating state intervention for institutions with large financial involvement in the derivatives market (e.g. AIG and Lehman Brothers). In effect, certain conditions can potentially undermine the stability of the financial system (network externalities). For example, ounterparty risks, pro-cyclical margin requirements (linkage with credit ratings) and the opaqueness of financial exposures on the OTC market may spread fear of insolvency, drying up liquidity from the markets and triggering disruptive 'cascade effects' on the whole system (FSA, 2009a; European Commission, 2009b). The collateral typically provided in cash net value is updated on a market-to-market basis, while funding through derivatives involves a flow of pay-offs in the long-term. This mismatch between liabilities and assets may accelerate liquidity crises sparking concerns over the real exposure of market players and fuelling mechanisms of adverse selection. ${ }^{37}$ The opaqueness of the OTC market (especially concerning counterparties' exposure) helps to nourish this uncertainty. Therefore, as the financial conditions worsen, market participants become more risk-averse, cutting exposures and leverage, and thereby pushing a further decline in prices and liquidity in the system (on endogenous risk, see Danielsson \& Shin, 2003). The reduced amount of resources in the system, therefore, tends to worsen credit risks and the asset side of balance sheets (drop in asset prices), ${ }^{38}$ calling for further margins or collateral injections. This unstable situation lowers liquidity and feeds the further reduction of resources in the system (Goodhart et al., 2008; see also figure below). The lack of liquidity dramatically affects market efficiency.

\footnotetext{
${ }^{36}$ We use the common market definition for 'exposure': the "netted mid-market mark-to-market (MTM) value of the transactions in the portfolio between two parties" (ISDA, 2010a, p. 3).

${ }^{37}$ See Akerlof (1970, pp. 488-500).

${ }^{38}$ Protective action on the part of investors to sell their linked assets, in a 'herd behaviour' manner, can become hazardous, spreading negative spillover effects onto other market players (so-called 'endogenous risk'); see Danielsson \& Shin (2003).
} 
Figure 7. The effect of the OTC derivatives markets crisis on

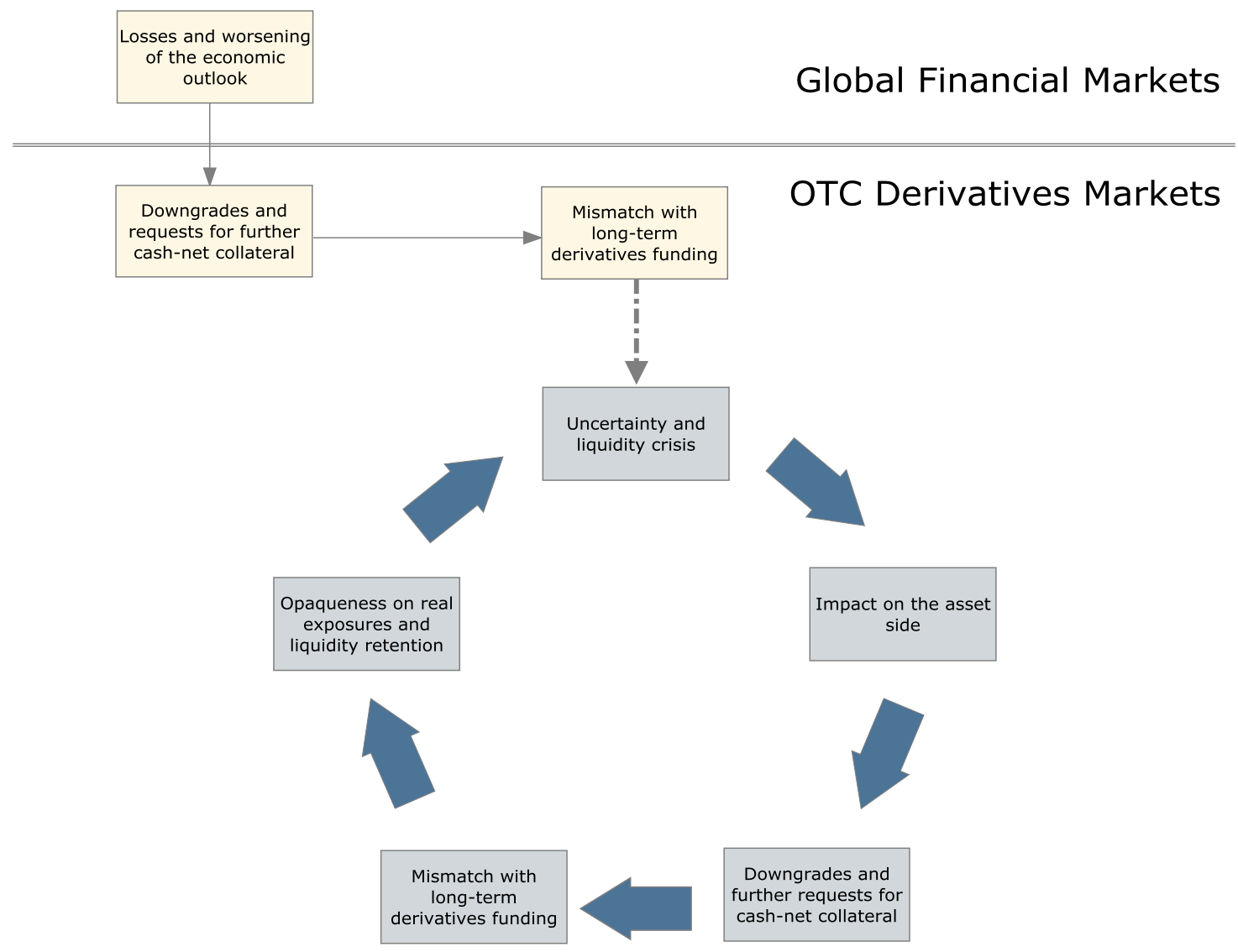

Source: Author's elaboration.

In theory, this vicious circle may also accelerate without the impact of huge direct losses in the market for derivatives. Trust and confidence in the efficient functioning of financial markets play a crucial role. The pro-cyclical aspects of the derivatives market may become a source of systemic risk. In this overall context, also non-financial institutions become part of the web of mutual dependence (European Commission, 2009d). The main way to stop the vicious circle, therefore, is to improve the general economic outlook in the underlying market. For instance, AIG is recouping over $\$ 3$ billion of collateral thanks to the turnaround in the securities market and generally in the underlying variable of many derivatives transactions. ${ }^{39}$ Whether or not one was dealing with regulated or unregulated entities seems finally to have no consequence for the final outcome. On the one side, the lack of transparency is exacerbated when derivative contracts are sold to unregulated entities (e.g. hedge funds), which make large uncollateralised exposures difficult to detect and create uncertainty around hidden exposures (Cecchetti et al., 2009). On the other side, with regard to systemic risks, important regulated entities - such as AIG -showed less commitment to devote resources such as collateral and to clean up their exposures through extensive use of complementary services.

\footnotetext{
39 “AIG recoups collateral”, Wall Street Journal, 29 October 2009 (www.wsj.com).
} 
Figure 8. Breakdown uncollateralised exposure

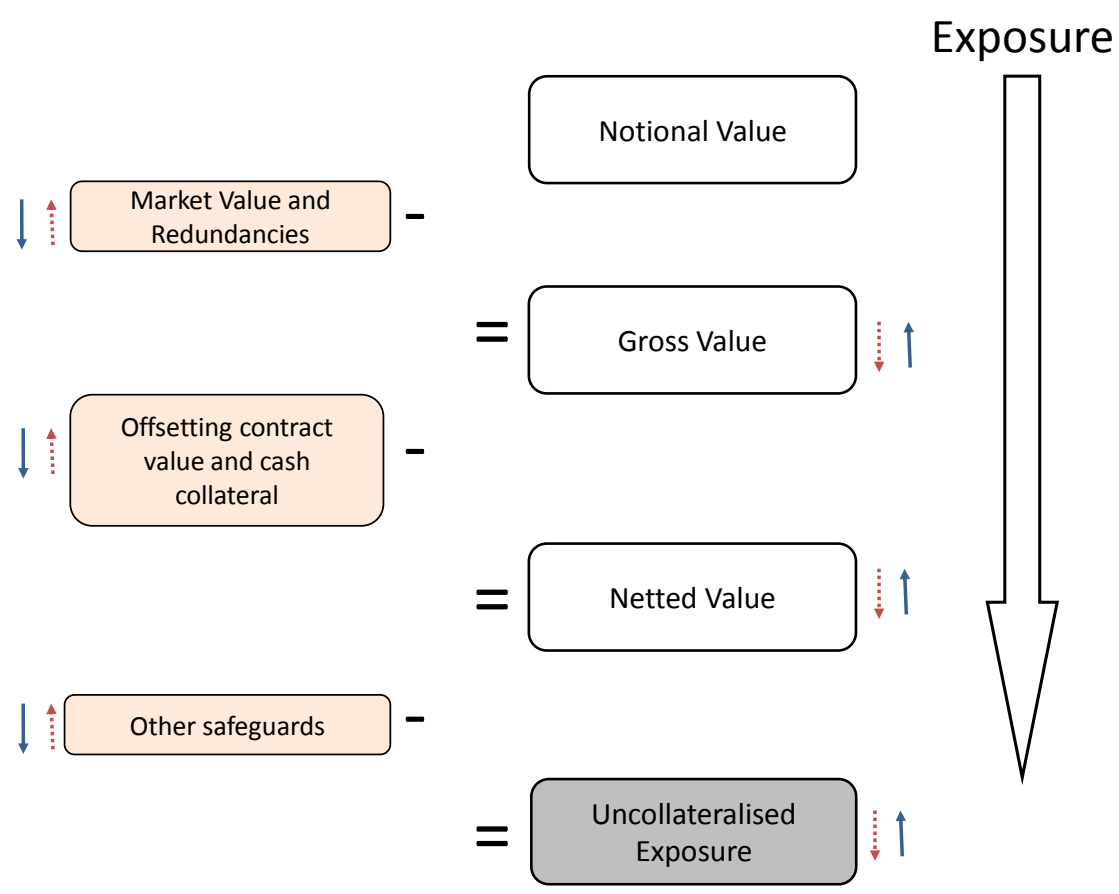

Source: Author's elaboration.

In effect, systemic risk in this market is connected to:

- the value of underlying markets

- liquidity and

- counterparty risk.

First of all, as shown in the figure above, the gross value, which represents a rough measure of exposure to these products, tends to increase and approximate the notional value if the fair value of these contracts goes down. The financial crisis, in effect, pushed up the gross market value of the exposure to all OTC derivative transactions by $58 \%$ between June and December 2008, even though the notional value went down by $20 \%$. The relative size of the gross amount grew from June 2007 to December 2008 by circa $173 \%$ to $6 \%$ of the notional value. The market value (fair value) of underlying assets becomes the first source of systemic risk and it creates a 'leverage effect' on the real exposures as the economic outlook worsens.

Figure 9. Notional versus gross value

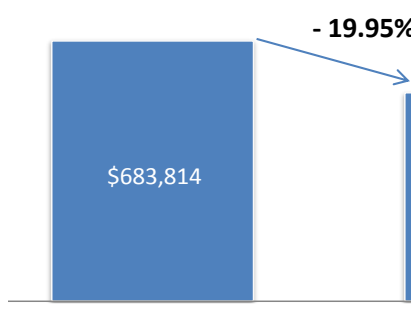

Jun.2008

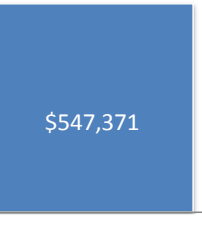

Dec. 2008

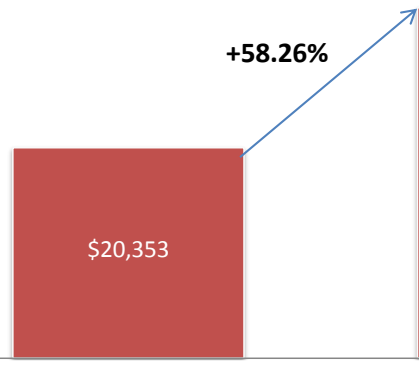

Jun.2008

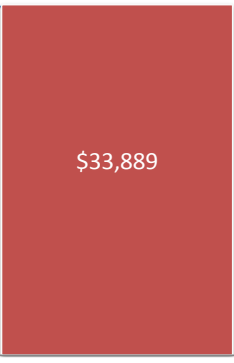

Dec.2008 


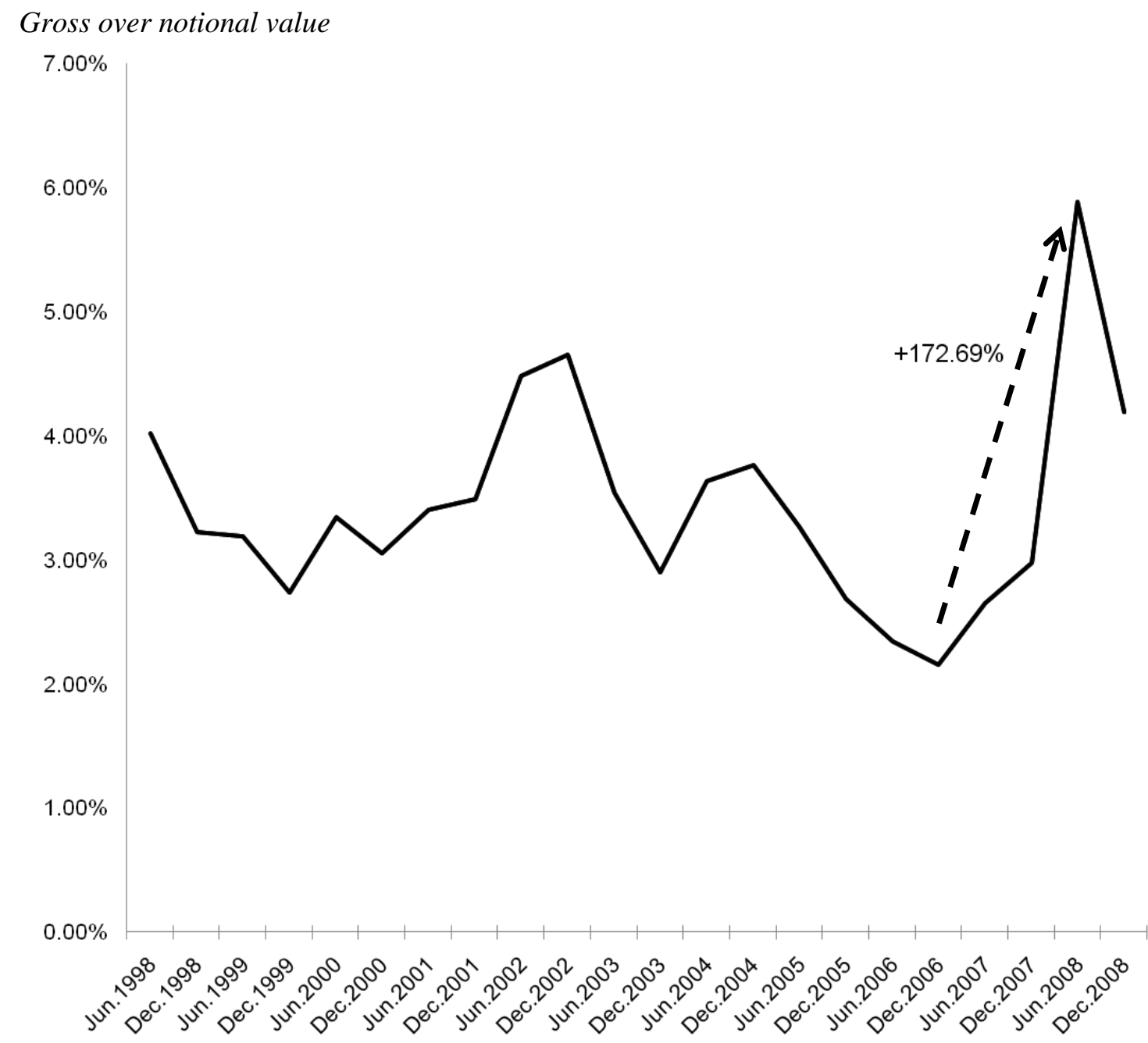

Source: BIS (2009).

Secondly, liquidity has a great impact on OTC derivatives contracts, as it helps to offset customised contracts in order to drastically reduce the exposure before netting with cash collateral. An exposure can be a source of systemic risk as long as the customisation is so complex (e.g. different maturities or idiosyncratic risks) that the counterparty cannot easily net part of its exposures with other held OTC contracts.

Lastly, counterparty risk can harm the whole financial system if the interconnectedness of financial institutions is strong enough to trigger 'cascade effects' between them. The absence of legal certainty around specific safeguards, cash collateral and other risk-reducing agreements, then, may not completely shield transactions from creditors' claims when one of the counterparties files for bankruptcy, becomes insolvent or disputes the verification of a credit event. In effect, the failure of one institution leads to information asymmetry that freezes the market by sparking concerns about the integrity of other financial institutions. The use of services such as netting and collateral management thus may be helpful, since they reduce the exposure of the financial or non-financial institution to counterparty risk and increase transparency of the real exposure and the interconnection between financial institutions. However, as previously mentioned, these services reduce counterparty risk as long as close-out agreements are in place (Bliss \& Kaufman, 2005). Close-out procedures, as described above, impact on outstanding contracts and involve the termination of the contract, once the credit 
event has occurred. This event is usually counterparty insolvency, but it may also be a downgrade or debt/firm restructuring. The sudden termination of outstanding contracts should be supported by the legal framework in the agreed jurisdiction. Once the legal support is obtained (which is still lacking in some countries), the outstanding amounts can be netted and transactions are terminated. In this way, counterparty risk is drastically mitigated as the net debtor or creditor will better manage transactions with lower probability to get into bankruptcy procedures, with high risks of procedural delays and amplified knock-on effects.

\section{Legislative actions in the EU and the US}

The G-20 commitment ${ }^{40}$ to a safer financial system pushed governments consider relevant regulatory intervention in the market for OTC derivatives. The aim is to strengthen their safety through standardisation and central clearing, as well as to increase international coordination and cooperation.

The current proposals in the EU and the US share common policy targets: centralisation, disclosure and limited access to OTC derivatives. However, the devil is in the details, and in the end the regulatory approaches of both parties could substantially diverge. Although the main features of these reforms have already been set up, the as yet embryonic stage of the European proposals does not allow a close comparison with the US approach.

In the US, three main legislative texts have been circulated in recent months, and the House of Representatives has approved a final version, submitting it for approval to the US Senate. In the EU, the European Commission drafted two Communications (July and October 2009), but the first legislative proposals will not surface until mid-2010. Regulatory intervention in the US will be accomplished through ad hoc regulation, while in the EU the Commission will amend existing directives and propose new specific rules. Both regulators, however, aim at ensuring financial stability for OTC derivatives, as the world's largest financial market (European Commission, 2009 a,b,c; US Treasury, 2009).

In order to achieve this ultimate goal of financial stability, the European Commission has set four intermediate targets (European Commission, 2009d):

1. increasing standardisation,

2. promoting the use of organised venues,

3. strengthening solutions for mitigating counterparty credit risk through centralised platforms, such as CCPs, and

4. increasing transparency through a more widespread use of trade repositories.

In this regard, the Commission elaborated a set of actions, listed below, to achieve these intermediate targets (see Table 4).

The US Treasury plan (US Treasury, 2009) set four relevant objectives, all of which were preserved in the legislative proposals and final text, except for the last one. These targets were:

1. preventing the activities in the OTC derivatives market from posing a risk to the financial system,

2. promoting efficiency and transparency of that market,

3. preventing market manipulation, fraud and other market abuses and

${ }^{40}$ See G-20, "Declaration on strengthening the financial system", London Summit, 2 April 2009 (http://www.londonsummit.gov.uk/resources/en/PDF/annex-strengthening-fin-sysm). 
4. ensuring that OTC derivatives are not marketed inappropriately to unsophisticated parties.

The first two proposals, therefore, envisage a set of measures to achieve greater transparency and a more stable and safer market infrastructure, in order to mitigate counterparty risk and to encourage a more responsible use of these complex instruments.

On both sides of the Atlantic, the OTC derivatives market seems to be a source of major concern for financial stability, while more standardisation, transparency and supervision, and stricter requirements are regarded as the means to create a more resilient market infrastructure (US Treasury, 2009, European Commission, 2009 a, e). European and US regulators are adopting a comprehensive policy approach, moving across asset classes. Interconnections and the global nature of this market, however, make a global and coordinated approach between Europe and the US indispensable. More should be done to assess the merits of the two proposals, as there is a vague idea in circulation that some market solutions (such as CCPs) are able to reduce or eliminate counterparty risk. On the contrary, with these market solutions, counterparty risk is only redistributed to other market participants. And it is sometimes the case that this redistribution assigns counterparty risk to the entity that can not easily bear it.

As shown in Table 4, we have identified a list of functions in the OTC derivatives market that will be subject to regulatory and supervisory interventions:

1. Clearing

2. Conflicts of interest and governance

3. Standardisation

4. Trade execution

5. Reporting

6. Data repositories

7. Supervision

8. Conduct of business standards

9. Other requirements and exemptions.

As stated above, the EU and the US share a strong commitment to regulating the market, but their proposals differ in several important respects. For instance, although EU and US regulators converge on the necessity for clearing services to increase the use of centralised solutions (such as central counterparty clearinghouses, or CCPs), they actually diverge on the way to implement a centralised scenario. However, bilateral clearing will still be possible but with higher capital and margin requirements. The EU text does not foresee any exemption or discrimination between financial and non-financial companies.

\section{Clearing}

On the clearing side, OTC derivatives will be gradually pushed towards centralised solutions, mainly CCPs, as a result of broader consensus at global level, which had originally formed only upon credit derivatives. ${ }^{41}$ In effect, the extension of this formal endorsement to all derivatives

\footnotetext{
41 "We will promote the standardisation and resilience of credit derivatives markets, in particular through the establishment of central clearing counterparties subject to effective regulation and supervision", G-20, "Declaration on strengthening the financial system", London Summit, 2 April 2009, p. 3 (http://www.londonsummit.gov.uk/resources/en/PDF/annex-strengthening-fin-sysm). Centralisation of clearing for OTC derivatives has been requested and monitored by the G-20 and many other groups and
} 
products has been achieved with these two legislative proposals and confirmed at global level by the last progress report of the Financial Stability Board (FSB) ${ }^{42}$ In the EU, centralisation of clearing would push all standardised contracts on CCPs. There is no clarity yet from publicly available documents whether the definition of standardisation will be aligned with the definition of CCP-eligible derivatives. As mentioned in the conclusion of Box 1, mandating central clearing for all standardised products (which are a wider category than eligible products) will move risks that cannot be adequately managed to a vital 'quasi-public' network infrastructure (see below on standardisation).

In the US, however, contracts will be centrally cleared by derivatives clearing organisations (DCOs), ${ }^{43}$ only if both parties are dealers and/or major swap participants (MSPs), and after the approval of both the SEC (Securities and Exchange Commission) and CFTC (Commodities Futures Trading Commission). The acceptance by the DCO gives the legal power to impose central clearing. In addition, the authorities may also force a DCO to accept a specific derivative transaction, as they can take the final action over a dispute.

It is advisable that the eligibility of a derivatives product is assessed by the clearing infrastructure through its risk committee, whose membership is independent from the ownership, in particular if the model of governance is not based on users ownership. Mandatory regulatory approval may create unnecessary pressures to include specific products that, in the end, may not be safely centrally-cleared. Committing to general principles for the product eligibility is not consistent with the customised nature of these transactions and the specific risk profile of counterparties. Eligibility assessment should be done on a case-by-case basis and regulatory authorities should only verify that the procedures applied by the infrastructure are transparent and non-discriminatory.

\section{Conflicts of interest and governance}

Potential conflicts of interest in the clearing approval procedure between financial institutions and DCOs pushed the US authorities to insert an article in the legislative text that limits the stake of frequent swap users (so-called 'restricted owners') in the ownership of DCOs below $20 \%$ (Lynch amendment). In effect, the risk of conflicts of interest in the governance of financial infrastructure (such as a CCP) is a source of concern. ${ }^{44}$ The Lynch amendment was removed from the bill's text, following the proposal at Senator Dodd in March $2010 .{ }^{45}$ In any case, a rule limiting the stake of ownership in the infrastructure will not solve or mitigate the concern, as the potentiality to acquire the full control over the infrastructure will still be in the hands of two or a few financial institutions. As explained above (section 6.5), a CCP is a network infrastructure whose value comes from the quality of its members and less from the resilience of the company running the infrastructure. As long as regulation works to preserve this value, it should be seen as efficient. This amendment, which is circulating in Europe as

institutions at international level, even before the G-20 summit; for instance, see CRMPG III (2008, p. 125), FSB (2008, p. 6) and G-30 (2009, p. 53).

${ }^{42}$ FSB (2009, p. 10).

${ }^{43}$ DCOs and CCPs are two different categories of entities performing clearing services. For the sake of simplicity, in the text hereinafter, we will use the terms 'DCO' and ' $\mathrm{CCP}$ ' interchangeably, even though there are differences between them.

${ }^{44}$ On the governance of financial infrastructure, see Lee (2010).

${ }^{45}$ See Dodd's draft in footnote 48. 
well ${ }^{46}$ is not consistent with the economics of a $\mathrm{CCP}$ and it will not mitigate conflicts of interest. On the contrary, it may hamper market initiatives towards an efficient model for the governance of network infrastructures, i.e. the user-ownership model. In effect, a few big clearing members may acquire a sufficient stake in the infrastructure to extract as much benefits as possible from smaller clearing members, which will have little latitude to move on to another infrastructure, as they will suffer high switching $\operatorname{costs}^{47}$ (direct and indirect). Once it is decided to mandate specific products to centralised infrastructures, clearing members must be allowed to participate in the governance of the infrastructure. Their resources feed the default funds, which allow CCPs to operate in complex derivatives markets with enough capital. Whether or not this governance should give control to the members through per capita voting or on the basis of the resources invested in the infrastructure (e.g. default funds), this should be chosen by the infrastructure itself. In theory, a model of ownership that assigns more voting rights to financial institutions that commit more resources to the infrastructure may be the best interpretation of the trade-off between control and resilience of the network infrastructure. In effect, on the one hand, the more resources clearing members are willing to commit, the more resilient is the infrastructure and the more open is ownership (user-oriented). On the other hand, the more the financial institution wants to keep control of the infrastructure, the more this choice will cost, also in terms of indirect costs as there is a risk that less clearing members would be willing to commit resources in an infrastructure controlled by one or few institutions. Finally, once the model of ownership is defined, the risk committee should focus its attention on these platforms, which should be independent from the owners; , at the same time, however, owners should be able to express their views in the governance of the infrastructure. A user-owned infrastructure cannot be mandated, as it would mean the mutualisation of these infrastructures. However, clearing members should be aware of the benefits of a user-ownership model, which may in the long term offset the initial investment to acquire a mutual control.

\section{Standardisation}

With regard to standardisation, the US proposal does not define when a product should be considered 'standardised'. Then, the section stating that regulators should presume a product is "standardised" if cleared by the DCO has been removed from the final text. ${ }^{48}$ This would have

46 See Werner Langen's report for the Committee on Economic and Monetary Affairs of the EU Parliament

(http://www.europarl.europa.eu/activities/committees/draftReportsCom.do?language=EN\&body=ECON).

47 Several costs may obstacle switching infrastructure. The main ones are transaction costs (costs of bridging the new platform to the clearing member), "exit" costs, opportunity costs, and uncertainty costs.

48 This definition also differed from Congressman Barney Frank's discussion draft bill on OTC derivatives, where 'standardised' derivatives could be also non-centrally cleared, even though DCOs would be required to accept standardised products regardless of where the derivative is executed. See Barney Frank, To enact the Over-The-Counter Derivatives Markets Act of 2009, Discussion draft introduced to the House of Representative, 13 October 2009; hereinafter, "Frank's Discussion Draft" (see http://www.house.gov/apps/list/press/financialsves_dem/discussion_draft_otc.pdf). As indicated in Table 5, we will also refer to another discussion draft, hereinafter "Dodd's Discussion Draft”, from Christopher Dodd, Chairman of the US Senate Banking Committee, introduced to the House on 1 November 2009 (see http://banking.senate.gov/public/_files/AYO09D44_xml.pdf). There is also a third proposal submitted by Rep. Peterson, House Agriculture Committee; see http://agriculture.house.gov/inside/Legislation/111/JDG_372_xml.pdf. Finally, there is the text approved by the House of Representative on December 11th, hereinafter the "2009 Act", H.R. 4173, The Wall Street Reform and Consumer Protection Act of 2009, US House of Representatives (see http://thomas.loc.gov/cgi-bin/query/z?c111:H.R.4173).On 15 March 2010, Senator Christopher Dodd proposed a new bill for financial reform with a new text for the OTC derivatives legislation. Few relevant changes have been made to the text approved by the House last December (see Dodd's financial reform 
implied the same definition of standardisation and eligibility, which in reality are two different concepts (see Box 1). The proposal, in effect, asks the SEC and the CFTC to build a more detailed definition of 'standardised product', as not all standardised products are eligible to be cleared on CCPs, even though regulators can put pressure on CCPs to extend their definition of 'eligible product'.

In the EU, there is no definition of standardised products, which may also actually fall outside the control of the CCPs. The Commission will emphasise the role of incentives to invest in standardisation, standard contracts and procedures. In addition, as explicitly stated in its Communication, the Commission will put pressure on CCPs to align standardisation with eligibility, which may create unexpected risks. Pressuring CCPs to include as many standardised transactions as possible may pose a potential risk of including derivatives transactions on the CCP network that may not be suitable for central clearing or backed by institutions that are not sufficiently committed to the resiliency of the infrastructure. In effect, forcing the system to clear specific derivative transactions that, in a normal regime, would not have been accepted may weaken the whole network, as central clearing network infrastructures (such as CCPs) are based on mutual respect by market participants of all general requirements. The compliance with uniform and accepted requirements by all clearing members indirectly pushes clearing members to accept the mutualisation of losses, which represent the support of last resort for the whole platform. It is therefore important to keep the quality of clearing members and cleared transactions very high. Undue pressure on OTC derivatives products to become standardised, then, may concretely affect the ability of these products to satisfy customised risk needs. As explained above, investments and pressure should be focused on introducing and diffusing electronic and automated mechanisms in the post-trading area. For instance, the objective to reduce the duration of the whole cycle, with settlement, to an ideal $\mathrm{T}+1$ - at the latest - should be pursued.

Adverse selection ${ }^{49}$ may affect the system, as good clearing members will see increasing costs of clearing (due to reduced freedom for CCPs to define strict eligibility requirements for products and members) despite their unchanged compliance with the CCP requirements. These circumstances will gradually induce part of these clearing members to exit the platform or to substantially reduce their positions or to make regulatory arbitrage with other jurisdictions (the market for OTC derivatives is global in nature), since their risk is not correctly priced.

legislation available at http://banking.senate.gov/public/index.cfm?FuseAction=Issues.View\&Issue_id= 630c2b4a-ef2a-9ff3-5e79-bbe3c26422da).

${ }^{49}$ In Akerlof (1970), in effect, the classical example to explain this informational problem is the market for lemon cars. The adverse selection, in effect, arises when products of different quality (e.g. lemons and good cars; junk and good bonds and so on) are sold at a single price because of asymmetric information (inability of the buyer or lender to understand the real quality/risk of the cars/financial product or borrower), so that too much of the low-quality product and too little of the high-quality product are sold. In the market for lemons and good cars, for instance, the equilibrium will result in a market price (due to the inability of the buyer to understand ex ante the quality of the product) a bit higher than lemons' real value and consistently lower than good cars' real value. Hence, the market equilibrium, in the mid-term, will determine that only lemons are sold in the market. This important issue may basically freeze markets justifying mechanisms for signalling quality, such as neutral third-party informational tools (rating agencies, etc.), regulatory interventions or simply pre-sale services. See Pyndick \& Rubinfeld (2004, p. 616) and Kraakman (1986). 
Moral hazard, ${ }^{50}$ in addition, may induce some clearing members - whose acceptance by the $\mathrm{CCP}$ is mandated or pressured by regulation - to exploit this situation by making little effort to fully comply with the CCP requirements, as they feel somehow protected by the network or they just freely ride on other members' stronger commitment. Therefore, it should be clearly stated that mutualisation of losses should intervene only when the involved clearing members have put all their available resources into the transaction, even though it might be not enough. In a centralised scenario for clearing services, the platform itself may become 'too big to fail', also increasing moral hazard of the entities assigned to manage the infrastructure and provide the related services. In this case, the intervention of the central bank should be limited to specific situations, such as when the entity that is supposed to manage the infrastructure has already used all its own resources to save the network. However, this solution would not be adequate if the clearing member is structurally not able to comply with the regular requirements set by the CCP for joining the network, but acceptance of the infrastructure had become compulsory by law. Nor would it solve the potential problem of adverse selection, as described above. Stress tests must be periodically performed in order to verify that members and the infrastructure maintain the same efforts over time.

Furthermore, if the service provided by CCPs is recognised as a public good, ${ }^{51}$ with the risk of free-riding (moral hazard), some authors argue that a public-private partnership could be promoted to control the ownership and the governance of this infrastructure on the one hand, and enforce policies to face diverging incentives between members and the infrastructure and control systemic risks on the other hand (Rausser et al., 2009).

\section{Trade execution}

Turning to trade execution, both US and EU proposals push for centralised execution of derivatives trades. US legislation follows the general principle that every centrally cleared derivative transaction should move on a board of trade (exchange or alternative trading platform). The law also foresees that both counterparties should be swap dealers and/or major swap participants. Therefore, an occasional swap user, with no regular business or substantial net position or exposure, can trade over-the-counter on a bilateral basis and clear the transaction outside a DCO. In the EU, the Commission expressed a 'societal preference' for transparent trading venues and with strengthened risk management procedures (European Commission, 2009a, b \& c). All standardised derivatives should move on organised trading venues, as defined by $\mathrm{MiFID}^{52}$ (regulated markets, multilateral trading facilities and systematic internalisers).

\section{Reporting and data repositories}

Transparency plays a pivotal role in the forthcoming legislation. Most notably, a more transparent environment may bring the evolution of systemic risks under control, but it may also induce market participants to pursue more accurate internal due diligence and increase the

\footnotetext{
${ }^{50}$ Moral hazard is an informational problem related to the opportunistic behaviour of the more informed party, who tries to exploit the informational advantage and the scarce ability of the less informed party to monitor the other's activity. See Holmstrom (1979) and Milgrom \& Roberts (1992).

${ }^{51}$ DCOs (e.g. CCPs) are gradually becoming public infrastructure, as they are progressively providing non-exclusive services for market participants. The absence of competition, however, may be affected by mandating the use of the platform, increasing risk concentration on a few entities and creating inefficient distortive incentives. Trading markets, currently compete exclusively for profit.

${ }^{52}$ Markets in Financial Instruments Directive, EC Directive n. 2004/39 and implementing Directive (n. 2006/73) and regulation (n. 1287/2006).
} 
quality of risk management, which will not only be based on external resources, as has frequently been the case in the past.

In the US legislative proposal, recordkeeping and reporting requirements are stricter than previously (including audit trails and daily reporting). DCOs, data repository and authorities should publicly disclose aggregate positions, while private information can only be delivered to authorities on a confidential basis. Information on single transactions (and reference entities) is not relevant for public disclosure. This two-tier system helps to increase transparency without seriously affecting businesses. In effect, "if transparency requires trading [and business] strategies to be made public, so that their price impact becomes large [enough], then the survival of the market will be jeopardised" (Acharya \& Richardson, 2009). These authors have also argued (referring to the CDS market) that information on price, contract and counterparty exposures should be immediately available for authorities, while some of this information can be disclosed to the public only on a delayed basis.

The US text, in addition, mandates the use of data repositories only for bilaterally-cleared transactions. DCOs, in this way, have the further responsibility to provide reporting services with the same standards as data repositories. In the EU, the Commission focused more on transparency of price and positions and there is no clear statement whether a single position should or should not be publicly disclosed. The proposal could extend the reporting requirements set by Art. 25(3) MiFID to all OTC transactions. Both proposals mandate data repositories, but the US proposal mandates data repositories only for non-centrally cleared transactions, whereas the EU Communication states that data repositories should be used for all OTC derivatives transactions. The European Commission will also set stricter requirements to receive the authorisation in Europe as data repository. The supervision will be done by the new European Securities and Markets Authority (ESMA), formerly the Committee of European Securities Regulators (CESR). There is no limitation on the number of data repositories operating on OTC derivatives markets. Competition between multiple data repositories does not seem to be a source of concern on either side of the Atlantic, even though the US will probably converge on the DTCC model.

\section{Supervision}

On supervision, the US proposal promotes the supervision of securities-based swaps by the Securities and Exchange Commission and the remaining derivatives by the Commodity Futures Trading Commission (CFTC). The Federal Reserve (FED) will receive information from these two primary regulators and will enforce margin and capital requirements for banks, as defined by section 4(s)e. Authorities may establish position limits, ban 'abusive swaps' or prohibit access to the US financial system for specific institutions, in order to preserve the public interest and to protect investors. In Europe, it is not yet clear how supervision will be split between the new authorities. ${ }^{53}$ It would be problematic for the European Central Bank (ECB) to supervise CCPs, as the powers given by the Statute are limited. The European Systemic Risk Board will supervise systemic risks that the derivatives market poses for global financial systems. The powers that this authority will exercise in the context are not yet clear. The October Communication, then, reaffirms the importance of international cooperation at G-20 level to promote the convergence of regulatory standards.

53 For more information about the new supervisory system, please check http://ec.europa.eu/internal_market/finances/committees/index_en.htm. 


\section{Conduct of business}

On conduct of business standards, the European Commission has not yet taken a clear position, but the proposed extension of MiFID to the OTC market may provide a solid background of business conduct standards to apply to this area of financial markets. However, the derivatives market is different from the cash equity market in the nature of participants, products, investment targets, etc. Transparency requirements, instead, may share the same objectives in the two markets (e.g. better disclosure). MiFID requirements for the access to the infrastructure may be extended for the use of CCPs. In the US, instead, the legislative proposal foresees that the authorities will set general principles on disclosure, market manipulation and standard of care. To solve conflicts of interest, the House also approved an amendment that prohibits swaps users from holding a stake of more than $20 \%$ in a DCO, board of trade or alternative trading platform. This rule has a more general meaning, as it opens the discussion over the governance of financial infrastructure in a global market that is currently converging to concentrate risks on centralised solutions (consistently regulated and supervised).

\subsection{Other requirements and exemptions}

As indicated in the table on the following page, the two proposals list several other requirements, such as margin and capital requirements for bilateral transactions. In effect, the US regulator will increase capital and initial margin requirements for swap dealers and major swap participants (hereinafter MSPs) that do not use centrally cleared (customised) derivatives or with large exposures. A prudential regulator may, however, extend these requirements to non-swap dealers or MSPs. It is economically justifiable that for customised and bilateral transactions, more margin requirements may be required as the transaction could be riskier, due to a mutual mechanism of safeguards set up by the platform and the absence of a network able to provide more liquidity to the transaction. Then, the transaction itself - due to high customisation - could affect liquidity as it will not be easy to resell in the secondary market. Capital requirements, instead, may not meet justified concerns. Capital requirements are usually imposed on financial institutions whose core business is the exchange of financial flows. However, requesting non-financial companies to increase their capital requirements - especially in relation to transactions used for hedging purposes - can be costly and inefficient. In effect, capital charges help to discourage the use but they do not concretely increase the safety of the transaction (capital is subject to other creditors' claims, etc.). For this reason, the US proposal actually adds an exception (not present in the EU proposal) stating that positions held for hedging purposes should not be included in the definition of major swap participant. While one may question the potential wide impact of this exemption, the US regulator is clearly trying to find a solution to the effect that capital requirements may have on specific non-financial and global businesses.

In the EU proposal, there is a generic statement aiming to impose capital requirements and higher margins on companies without discriminating their final use. The proposal also asks for higher variation margins, which are usually set by participants once critical aspects of the transaction should suddenly change (they have a cyclical nature). It would be preferable to leave this decision to the market, in order to avoid unjustifiable interferences with their daily business. There is also the risk to increase the dependence of non-financial companies from the financial system, as they will need new lines of credit to satisfy stricter margin requirements (FSA, $2009 \mathrm{~b}$ ) or they may outsource the collateral management to a third party agent or directly to a custodian (ISDA, 2010b). In effect, the Communication then introduces an exemption from stricter variation margins for non-financial institutions whose use of derivatives is below a 'given threshold'. However, setting a threshold may dramatically split the market and also influence business models in case the level is too high or too low. These decisions should be usually left to the market. In addition, hedging transactions for non-financial companies are 
often fully compensated for by the revenues of the core business if the trend is going in the opposite direction of the hedged variable. Therefore, without a proportionate approach, hedgers will be more exposed to their risk profile than in the other scenarios, and perhaps they will be led towards alternative solutions that are not completely tailored around their risk management strategies.

Both sets of proposals call for increased market surveillance: in the US, through the abovementioned authorities and in Europe through the extension of the Market Abuse Directive to OTC derivatives (in particular to alternative trading platforms).

Concerning the problem of account segregation mentioned above, the swap counterparty, in US legislation, may ask the dealer to segregate the assets (margins and collateral) into a third-party custodian account or it should provide quarterly updates about its back-office procedures for collateral and margins. To be a 'third-party', the dealer or MSP should not hold more than 20\% of ownership or $50 \%$ of representation on the Board of the custodian that segregates the assets.

Finally, the US text sets a list of exemptions. First of all, a list of 'identified banking products' is exempted from this regulation, as they may already be under stricter or different regulation and requirements. Secondly, as mentioned above, positions held for hedging or risk management purposes should be excluded from this regulation. In this regard, regulators should set clear definitions of hedging and risk management purposes, as this rule may be used to circumvent the entire regulation. A residual exemption is granted to derivatives not accepted by the DCO (Derivatives Clearing Organisation) and/or approved by the authorities, as well as in the case when one party is not a swap dealer of an MSP.

To sum up, US and EU interventions appear to be following the same regulatory path, but in the end show striking divergences. Although motivated by a shared commitment, details in the current texts differ in the several important respects. EU and US market participants, on the other hand, call for a more proportionate approach and uniform reaction on a global level. In effect, before the crisis, financial institutions were already starting to channel derivatives transactions into CCPs. The US - seemingly more prescriptive with rules such as the one on conflicts of interest, which limits the ownership stake of financial institutions in the infrastructure - is adopting a legislative text that allows wide exemptions (as described in the table above). In Europe, conversely, there is still uncertainty about the final regulatory actions, but an approach that does not discriminate between market participants and products - as current proposals fail to do - may have devastating effects in comparison to the US legislative text. Nevertheless, MiFID and the capital requirements Directive (CRD), in particular, may be a valuable reference point from which to draft new regulations for OTC derivatives in Europe. Finally, the risk of patchwork regulation across the world's largest financial market is around the corner. It may create regulatory arbitrage and result in an inefficient final equilibrium. 
Table 5. US and EU OTC derivatives proposals: A comparison of key features

\begin{tabular}{|c|c|c|}
\hline & \multicolumn{2}{|c|}{ Financial Stability } \\
\hline & US & $\mathbf{E U}$ \\
\hline Clearing & $\begin{array}{l}\text { - All 'standardised' OTC derivatives are required by law to be cleared through regulated derivatives } \\
\text { - Alearing organisations (DCOs)**. } \\
\text { A swap shall be centrally cleared if accepted by a DCO and if both parties are dealers or major } \\
\text { - CFTC and SEC should approve which classes of derivatives will be centrally cleared, taking into } \\
\text { account different aspects (significant outstanding notional, availability of clearinghouses, etc; } \\
\S 113,(\text { a) (2) '(j)' (1)). DCOs are obliged to submit all swaps that are seeking to accept for clearing. } \\
\text { - DCOs should accept standardised products and considered centrally-cleared products with same } \\
\text { terms fungible to be offset if accepted by the CFTC and SEC }\end{array}$ & $\begin{array}{l}\text { - Pressure to bring standardised OTC derivatives on CCPs (e.g. CDSs from } 30 \text { July } \\
\text { on CCPs ). This provision should mandate standardised products on CCPs, but the } \\
\text { Commission needs to define which contract can be regarded as standardised (p. 6). } \\
\text { - Bilateral clearing is allowed but with more requirements - (COM '09a, p. 9). } \\
\text { - Ad hoc legislation for central counterparty clearing (CCPs) concerning: conduct } \\
\text { of business and governance (Conflict of interests, access, transparency, etc), risk } \\
\text { management standards, authorisation [EU passport], recognition of third-country } \\
\text { CCPs, and legal protection to collateral and positions (COM 'O9d, p. 4). }\end{array}$ \\
\hline Standardisation & $\begin{array}{l}\text { - The term 'standardisation' will be defined by SEC and CFTC. } \\
\text { - Presumption of standardisation if accepted by a DCO. } \\
\text { - Setting standards for customized trades and power for regulators to prohibit not standardised } \\
\text { products. }\end{array}$ & $\begin{array}{l}\text { - More standardisation also for non-CCP eligible OTC derivatives; } \\
\text { - Standardisation to achieve through: incentives to invest in standardisation; standard } \\
\text { contracts (also on bilateral basis) - (COM '09a, p. 9-10; '09b, p. 3). Plus } \\
\text { standardisation of legal regimes (COM '09d, p. 10). }\end{array}$ \\
\hline Trade execution & $\begin{array}{l}\text { - Only Eligible Contract Participants (ECPs) can trade derivatives over-the-counter (entering in a } \\
\text { contract). } \\
\text { - Trading of derivatives must move on a board of trade if they are centrally cleared and both } \\
\text { counterparties are swap dealers and/or MSPs. }\end{array}$ & $\begin{array}{l}\text { - Societal preference for transparent and competitive trading venues (as exchanges), } \\
\text { namely where trade-related information is publicly disclosed and risk management } \\
\text { is consistently strengthened - (COM '09a, p. 12). } \\
\text { - All standardised derivatives should be traded on organised trading venues (as } \\
\text { defined by MiFID, excluding Crossing Networks), where appropriate (COM '09d, p. } \\
\text { 8). }\end{array}$ \\
\hline Reporting & $\begin{array}{l}\text { - CFTC and SEC will impose record-keeping and reporting requirements (including an audit trail } \\
\text { and daily trading records) on all OTC derivatives. } \\
\text { - DCOs, data repositories and CFTC (under Section 4r) should promptly disseminate reporting } \\
\text { (aggregate data) on trades, prices and other information on a confidential basis to primary } \\
\text { regulators (CFTC, SEC) - (OTC Act '09 §715, UST '09, p.48). } \\
\text { - In transactions where counterparties are or dealers or MSPs, both shall report the transaction. If } 1 \\
\text { only is dealer or MSP, this part shall report the transaction. If neither parties are dealers or MSPs, } \\
\text { only } 1 \text { party should be required to report the transaction to trade repositories or the Commission, if } \\
\text { not centrally cleared. }\end{array}$ & $\begin{array}{l}\text { - Increasing market transparency on: positions (complete only on single institutions } \\
\text { and case-by-case); prices (available to market participants via inter-dealer brokers; } \\
\text { also post-trade information). } \\
\text { - Improving information reporting (extending art. 25(3) MiFID to derivatives with } \\
\text { underlying based on financial instruments listed on exchanges or to all OTC } \\
\text { transactions) - (COM '09b, p. 9-11). }\end{array}$ \\
\hline Data Repository & $\begin{array}{l}\text { - A regulated trade repository must be used for derivatives not cleared on DCOs. Both } \\
\text { counterparties should report to it. } \\
\text { - More than one repository is implicitly allowed, while they will be requested to register and } \\
\text { comply with specific duties. }\end{array}$ & $\begin{array}{l}\text { - Use of data repositories should be mandated for all transactions (if not traded on } \\
\text { exchanges or centrally cleared) to increase transparency (on prices, transactions } \\
\text { and positions) and reduce operational risks (p. 7) } \\
\text { - Regulated on the operative side, covering authorisation/registration, access and } \\
\text { participation to the repository, data quality and timeliness, access to data, } \\
\text { safeguarding of data, legal certainty of registered contracts, governance and } \\
\text { operational reliability. This control should be done by CESR/ESMA. Authorisation } \\
\text { should be also requested for third-country repositories in the EU on the principle of } \\
\text { "equivalence" (COM '09d, p. 7-8). }\end{array}$ \\
\hline Supervision & $\begin{array}{l}\text { - CFTC and SEC will be primary regulators, working to harmonize futures and securities regulation } \\
\text { on swaps, to police market, and to limit access for unsophisticated counterparties. } \\
\text { - SEC to supervise security-based swaps, CFTC to supervise the rest. Disputes to be solved by the } \\
\text { Financial Services Oversight Council. }\end{array}$ & $\begin{array}{l}\text { - No final statements on supervision; decision has been referred to ad hoc legislative } \\
\text { proposals (after the De Larosiere report), which are going to shape also the } \\
\text { supervisory aspects of derivatives markets. } \\
\text { - ECB for supervision on CCPs? Problems with statute. }\end{array}$ \\
\hline
\end{tabular}




\begin{tabular}{|c|c|c|}
\hline & $\begin{array}{l}\text { - FED will be secondary 'prudential regulator', getting information from primary regulators; it } \\
\text { oversights market infrastructure, and has to enforce the provisions on capital and margins in } \\
\text { section 4(s)e. } \\
\text { - CFTC may establish position limits and other restrictions for the public interest in order to face } \\
\text { 'excessive speculation'. } \\
\text { - SEC and CFTC can ban 'abusive swaps' and the 'access to the United States financial system' for } \\
\text { entity domiciled in a specific country; they can impose position limits or accountability for public } \\
\text { interest and protection of investors. }\end{array}$ & $\begin{array}{l}\text { - The European Systemic Risk Board will supervise the systemic risks that } \\
\text { derivatives markets pose to the whole financial system - (COM '09a, p.8). } \\
\text { - More international cooperation at G-20 level, in order to avoid regulatory } \\
\text { arbitrages and lead to the convergence on regulatory standards (COM '09d, p. 3) }\end{array}$ \\
\hline $\begin{array}{l}\text { Business Conduct } \\
\text { Standards }\end{array}$ & $\begin{array}{l}\text { - General business conduct standards and requirements on disclosure, market manipulation and duty } \\
\text { of care prescribed by the Commission. }\end{array}$ & None \\
\hline $\begin{array}{l}\text { Other Require- } \\
\text { ments }\end{array}$ & $\begin{array}{l}\text { - Customised OTC derivatives should not be used to avoid using a DCO (severe controls on it). } \\
\text { - Swap dealers and MSPs using customised OTC derivatives (not accepted by DCOs) or with large } \\
\text { exposures will comply with higher capital charges, dual registration, business conduct standards, } \\
\text { prudential supervision and initial margin requirements. Prudential regulator and Commissions for } \\
\text { bank swap dealers or MSPs and non-bank will set capital charges more than zero for centrally- } \\
\text { cleared derivatives and higher for non centrally-cleared derivatives. Initial and variation margins } \\
\text { also should be imposed to them for non centrally-cleared transactions. (H.R. } 4173 \S 117, \text { ' } \$ 4 \mathrm{~s}^{\prime} \text { (e)). } \\
\text { - Obligation of registration for DCOs, plus other duties (compliance officer, reporting, etc). } \\
\text { - Marketing to unsophisticated investors shall be regulated. } \\
\text { - At the request of a swap counterparty, the swap dealer shall segregate the assets as margin or } \\
\text { collateral into a 'third-party' custodian, or should report to its counterparty on a quarterly basis } \\
\text { about its back office procedures for margins and collateral. } \\
\text { - If a dealer or MSP owns more than 20\% (or more than 50\% representation in the board of } \\
\text { directors) of a custodian, the custodian should not be considered independent for the purpose of } \\
\text { - CFsets segregation (Lynch Amendment). } \\
\text { the definition of MSP. }\end{array}$ & 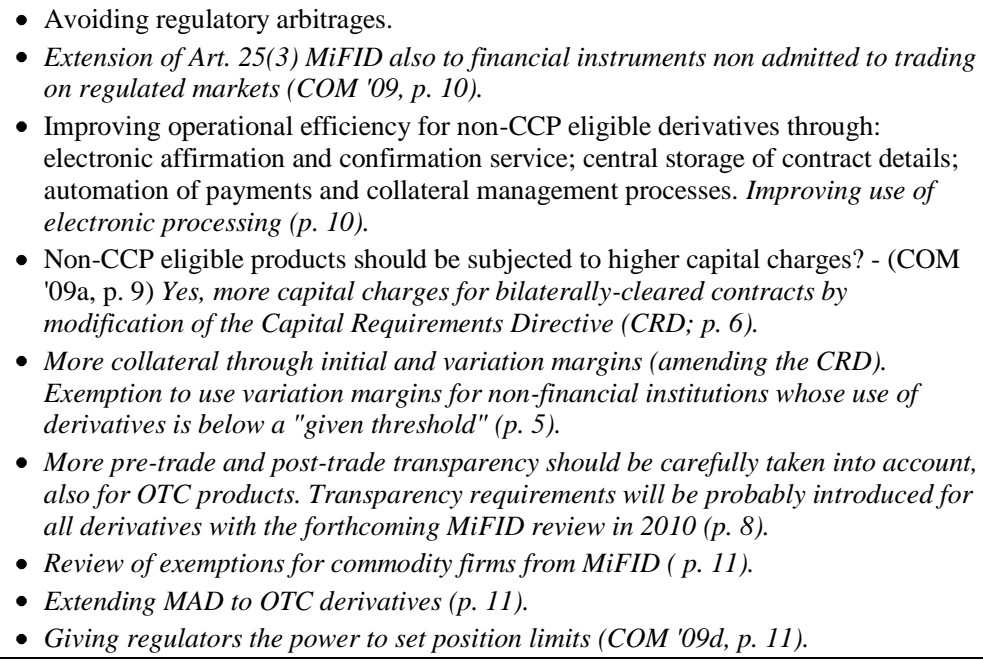 \\
\hline Other exemptions & $\begin{array}{l}\text { - No further capital charges or margin requirements if one of the two parties is not a dealer or MSP. } \\
\text { However, the prudential regulator may extend margin requirements also to swaps not cleared by } \\
\text { DCOs and to non swap dealers or MSPs; } \$ 117, \S 154) \text {. } \\
\text { - "Identified banking products" are exempted from this regulation }(\$ 113 \text { (c) (2)). } \\
\text { - The group of major swap participants should exclude positions held for hedging commercial risks } \\
\text { or risk management purposes. } \\
\text { - A swap may be exempted by central clearing on DCOs and trading on a Board of Trade if no DCO } \\
\text { accepts it or if one counterparty is not a swap dealer or MSP, or does not meet eligibility } \\
\text { requirements of a DCO. }\end{array}$ & None \\
\hline
\end{tabular}

*Underlined text is NOT included in the text approved by the US House of Representatives (H.R. 4173) and under discussion in the US Senate, which represents the most relevant measures proposed in the "Discussion Drafts" by Frank and Dodd, plus other legislative and non legislative texts. OTC Act '09 is the text introduced to the House on October 2nd.

** We will indifferently refer in the text to clearing agencies and derivatives clearing organisations as DCOs or CCPs.

*** In italics relevant measures proposed by the new Commission Communication on October 2009 (EU COM '09d)

Source: Author's own compilation based on Dodd's Senate Bill 2010, H.R. 4173 Act '09, October OTC Act '09, Discussion Drafts '09, COM ‘09a-b-c-d, UST ’09. 
Box 3. The Volcker rule: A big cloud over OTC derivatives markets

The financial crisis called into question the stability and safety of the financial system. Several reforms for the banking system are under discussion at G-20 level, a few of which have been endorsed or are currently being evaluated by relevant national governments (JP Morgan, 2010):

1. Volcker rule for US banks (Volcker, 2010)

2. Separation of activities (narrow banking)

3. Basel III proposals

4. Solvency II proposals in the European Union

5. Increased liquidity and leverage requirements

6. Proposals for dynamic provisioning

7. Proposal for new taxes (such as the liability tax and the Tobin tax)

Any one of these proposed reforms would have an impact on the market for OTC derivatives, but the greatest long-term structural impact can be expected from the Volcker rule, proposed by the former Chairman of the Federal Reserve (1979-87) and currently Chairman of the Economic Recovery Advisory Board created by the Obama administration. This proposal aims at restricting the engagement in proprietary trading and the ownership or sponsorship of hedge funds and/or private equity funds for FDIC depository institutions, in order to prevent non-bank financial institutions from free-riding public guarantees and support.

As shown in the table below, the measure will have a major impact on investment banks, which will see $10 \%$ of their investment revenues (as pure proprietary trading) almost disappear (-85\%, which is the estimation made by JP Morgan). Following Volcker's proposal, financial institutions will never regain this profitable business unless they are willing to run it in a separate and distinct entity.

\section{The impact of Volcker rule on global banks}

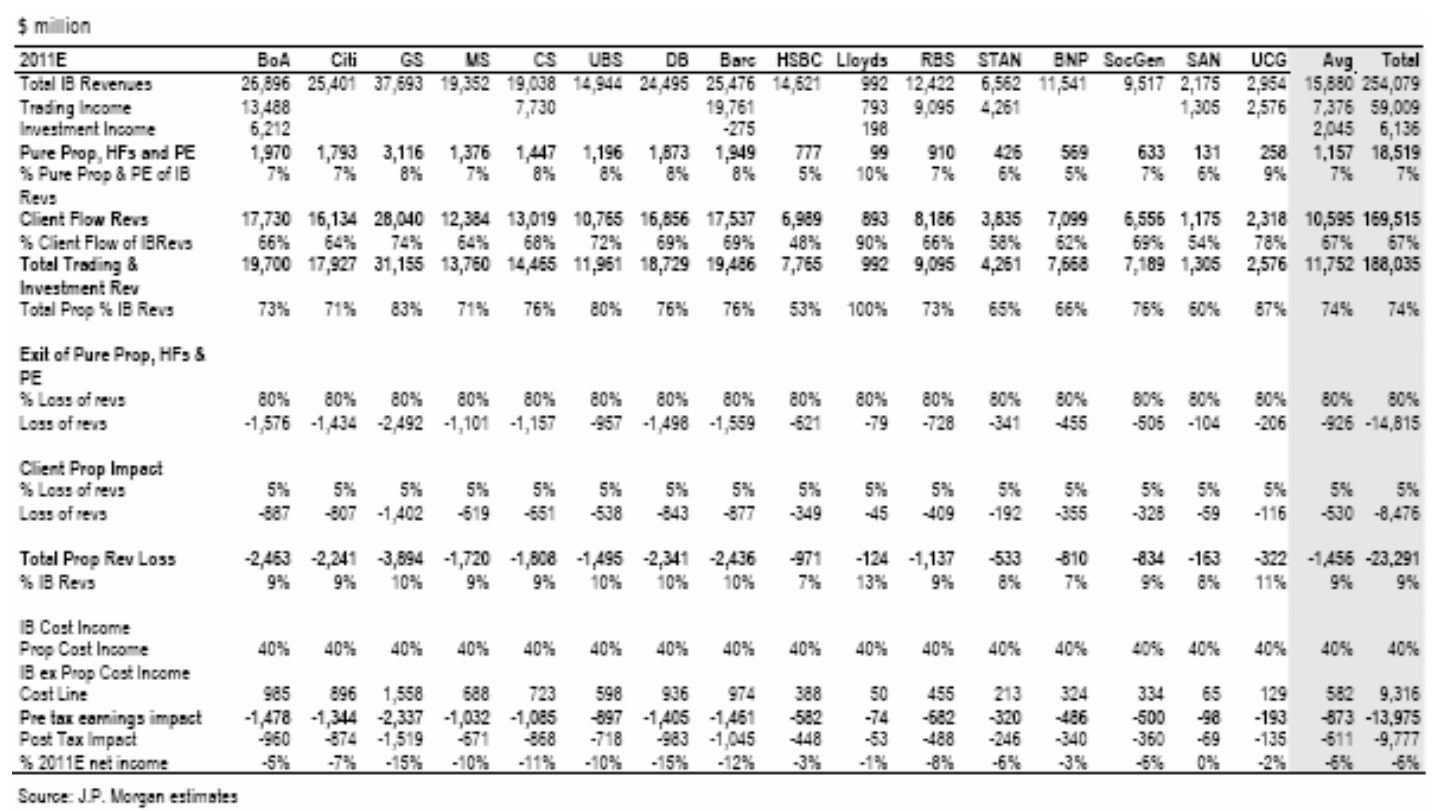

It is not possible to quantify the impact of the Volcker rule on OTC derivatives markets but the proposal is currently limited to proprietary trading activities. Dealer-broker activities should only indirectly be affected by this proposal (through a potential lower level of bank activities on proprietary trading). The financial infrastructure of OTC derivatives markets should remain intact even if the US government adopts the Volcker rule, the full impact of which can only be evaluated once the final terms are approved by the US Congress. 


\section{Prospects for the OTC derivatives market: Four scenarios}

As a result of the proposed regulatory interventions, the market for OTC derivatives may evolve towards one of four possible scenarios (or a combination there of), diagrammed in Figure 10:

- Pure OTC derivatives

- Centrally-cleared OTC derivatives

- Disclosed and highly collateralised bilateral transactions

- Exchange-traded derivatives.

These scenarios are designed around the role of regulation and central clearing to pursue a specific outcome. In effect, regulatory actions and the move on central clearing may involve stark trade-offs, such as liquidity vs. disclosure and customisation vs. standardisation. In effect, liquidity - the most important characteristic of the OTC derivatives market - may be affected by excessive disclosure on single positions since it is primarily professional investors who deal with this market. ${ }^{54}$ Derivatives transactions that can reveal business strategies may be pushed out of the market. Reducing counterparty risk through massive standardisation and increasing transparency through excessive disclosure may affect respectively customisation and market liquidity. These scenarios are not mutually exclusive, but they can cohabit in the OTC derivatives market.

Figure 10. OTC derivatives matrix

\section{Liquidity}

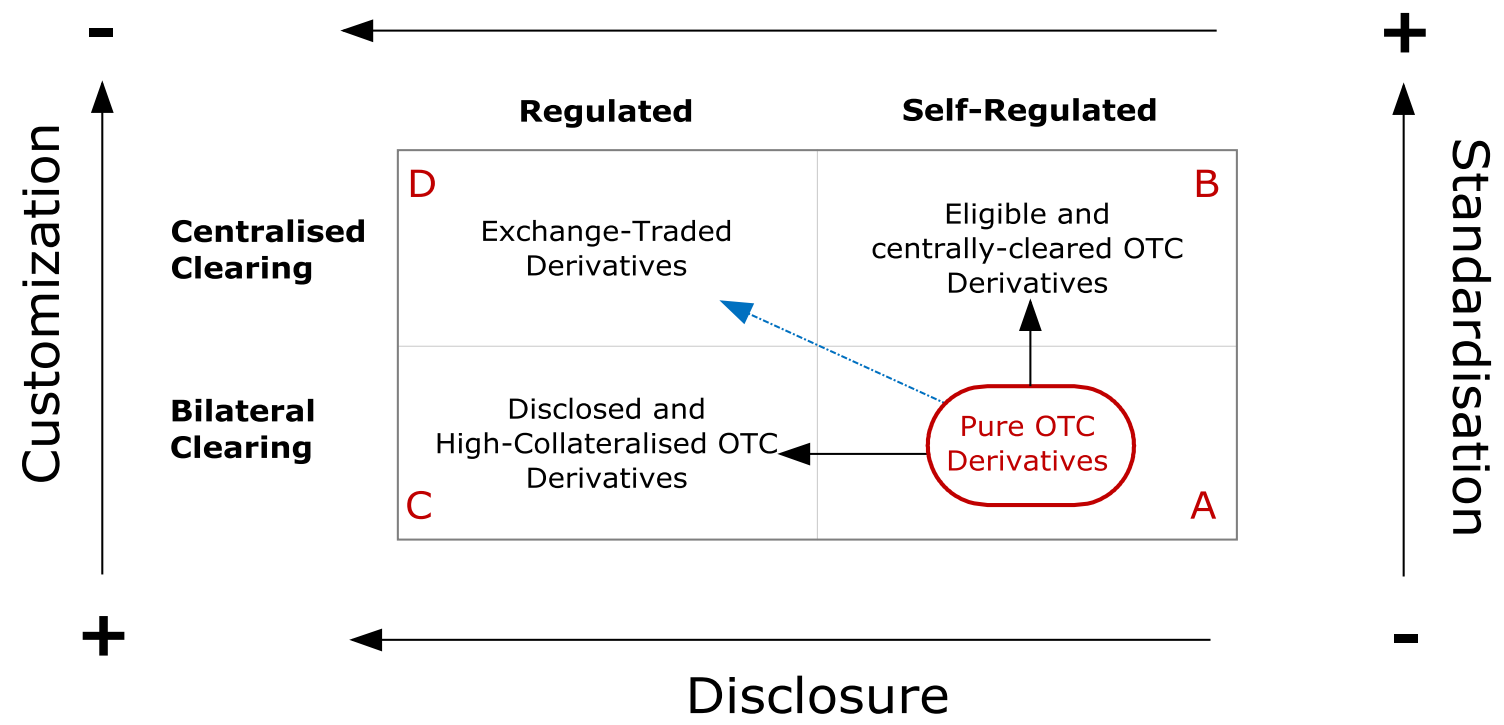

Source: Author's elaboration.

\subsection{Scenario A}

The first scenario is the current one, i.e. before any regulatory intervention has taken place. OTC derivatives are mainly traded and cleared on a bilateral basis and transactions are highly customised (even bespoke), in order to meet specific risk profiles or investment decisions. This

\footnotetext{
${ }^{54}$ In markets where retail investors are largely involved, however, the outcome may be the opposite; for instance the bond market is a good example how the shift from both retail and professional markets to an OTC-professional market has affected the liquidity of the market itself (see Biais \& Green, 2007).
} 
flexibility does not restrain the possibility to trade vanilla and highly standardised products, which actually represent more than $2 / 3$ of the market (Nystedt, 2004). Disclosure is mainly selfregulated (unless derivatives are backed by securities regulated in the underlying market) and limited to market initiatives (such as the DTCC model), that publish only some aggregate data. There is little chance that this scenario will survive the coming regulatory wave that will make disclosure tighter and/or reduce the options of customisation of the final product (through centralisation and standardisation).

\subsection{Scenario B}

The second scenario consists of moving the clearing of derivatives transactions to central platforms, such as CCPs. These platforms create an infrastructure that can work efficiently if products satisfy eligibility requirements. These requirements do not exclusively depend on standardisation, and it will take time before the pressure to centralise clearing services for most derivative products will have knock-on effects aimed at promoting more product standardisation and allowing a straight-through-processing and faster handling of the transaction. As defined in the US proposal, disclosure will still be done through the platform, which has its own reporting standards (self-regulated) to disclose aggregate data. Participants will not be asked for more disclosure on single trades (if not requested by regulators and on a confidential basis). This scenario should thus preserve liquidity, since liquidity is one of the pre-conditions for accessing the platform (see Box 2). However, mandating central clearing without taking into account the many diverse requirements to efficiently process the transaction through the platform may increase the cost of trading, reduce liquidity and affect the resilience of the infrastructure. It is up to regulators, through consultation with market participants, to define the extension of this obligation. Some aspects of current EU proposals may subject specific infrastructures to unnecessary risks, affecting the ideal and efficient scenario B. For instance, the absence of a different regime for non-financial institutions and a legal text without exemptions may be a source of concern. The inefficient concentration of risks on CCP platforms may stifle innovation and provide few incentives to foster competition.

\subsection{Scenario C}

The third scenario represents an attempt to devise a perfect compromise between customisation and disclosure. There are highly customised transactions that cannot be cleared on CCPs (e.g. bespoke transactions), but they should be preserved since they can be vital for hedging and risk management purposes (e.g. commodity derivatives for energy companies). However, for this scenario, regulators will prescribe stricter reporting and record-keeping requirements, as well as tougher capital and margin requirements. This outcome will reduce liquidity as derivatives users (especially non-financial ones) will face higher costs to access these financial instruments. Consequently, this may reduce incentives to invest in automation and standardisation of the products that have not been accepted for clearing on CCPs. In effect, the incentive of market participants to promote further standardisation of bilaterally-cleared transactions will be reduced if they do not offer substantial benefits to offset the increasing costs, due to tougher regulation. The benefits needed in order to invest in standardisation for bilateral transactions will be reset at a higher level, since the cost at trading standardised (but ineligible) transactions bilaterally will be higher as well. A potential outcome may be that a growing number of derivatives transactions will no longer be traded bilaterally, increasing the risks for firms that cannot find valuable alternative hedging solutions for their risk profile or increasing their costs, as they have to modify their business model to use an alternative product. Conversely, if regulators mandate central clearing of standardised products, the outcome will present the efficiency issues mentioned above. Regulators should therefore work to find a better equilibrium between scenarios B and C. 


\subsection{Scenario D}

The last scenario consists of the mandatory execution of derivatives trades on regulated venues with centralised trading and clearing, such as exchanges. ${ }^{55}$ These platforms may provide market participants with a transparent pool of liquidity, centralised clearing and highly standardised terms and conditions. However, the risks for the survival of these markets (if one carefully considers the reasons behind the use of OTC derivatives products) are directly magnified by the indirect imposition of a uniform model of standardisation for derivatives products. Then, the few opportunities to find customised products that can cope with specific risk profiles, plus the cost of a heavier regulatory framework, can make things worse. The limits to customisation may sound the death knell for the OTC derivatives market. The risks of stifling financial innovation and then of influencing business models are very high. In addition, there may not be enough liquidity to sustain the OTC market on exchanges (FSA, 2009b). As described in section 4, the market structure has supported its growth and development through a network of dealers, thereby making the use of OTC derivatives widespread between financial and non-financial institutions. In effect, an exchange will unilaterally redefine available economic, legal and technical terms of the product (Culp, 2009), aligning it with the primary needs of the infrastructure and not with the needs of the counterparties.

This scenario could only be efficient for products that do not require much flexibility, have a large size and already show very high volatility. These products can be indexes, such as the ones run by financial institutions in the credit default swaps market. For other products, the characteristics provided by these execution venues may not be requested by the market, creating an inefficient outcome. The exchange will also define the access rules to the platform and handle transaction reporting with no interaction from the counterparty. Products will be shaped in a different way from that originally requested by the demand creating the market (customisation and flexibility). In this way, counterparties will somehow be forced to adapt their business models to the transaction; otherwise, they will be pushed to leave the market (if bilateral transactions are too costly) or to use alternative and costly financial products. For instance, an airline company that wants to obtain protection with a customised derivative transaction for a specific time frame, size and combination of underlying variables will probably need to access a similar product, exposing itself to the risk that this completely non-customised product may not efficiently hedge its business risk. In addition, the OTC market always represented an alternative to exchanges and organised venues. With a mandatory solution, competition may be irremediably harmed, discouraging innovation in trading technologies and product development.

In conclusion, this scenario should not be mandatory and should be limited only to certain kinds of products. Since the benefits of this scenario are currently unclear and the costs of this choice are extremely high (FSA, 2009b), regulators should reconsider any kind of mandatory decision for derivatives execution, to avoid irremediably altering the structure of the market. The recent financial crisis has showed that liquidity is the most important element in the derivatives market. Any intervention to shape their structure should give priority to preserving conditions that allow the market to be deep. The concentration of credit risk due to customised transactions limits the possibility to access the secondary market in case of insolvency problems. Derivatives transactions can be centralised on organised trading venues as long as limited possibilities to customise products will not affect the overall liquidity and flexibility of this market, therefore also affecting centralised clearing platforms, which suffer more than trading platforms from the absence of a liquid market.

\footnotetext{
${ }^{55}$ The assumption is that alternative trading platforms will be regulated in the same way; there could be alternative equilibria with different results.
} 


\section{Conclusions}

So far OTC derivatives markets - by definition - were largely unregulated or poorly regulated. In the aftermath of the financial crisis, however, regulators are taking momentum to reform aspects of this huge systemic market. OTC derivatives combine economic and legal risks and represent the most complex instruments in financial markets. These risks can be classified as idiosyncratic or external, in order to understand how responses should be addressed. Three important factors may have devastating effects on this market: 1) illiquidity, 2) counterparty risk and 3) legal uncertainty.

In its assessment of the major proposals to reform the OTC derivatives market, this paper arrives at the following policy conclusions, divided into three areas.

\section{Transactional aspects}

- The pre-trade phase of a derivatives transaction is crucial. It consists of drafting and selecting the economic and legal terms of the transaction. It is important that parties agree on terms and methodologies that are recognised and protected by legal rules in the relevant legal jurisdiction (e.g. bespoke transactions). A uniformly and globally valid master agreement may substantially reduce risk.

- Market interventions should push for wider adoption of an electronic system for verification and confirmation of trades, in order to minimise outstanding confirmations. Unconfirmed trades increase uncertainty on the enforceability and legal validity of the transaction. The target should be same-day confirmation or $\mathrm{T}+1$ at latest.

\section{Trading and clearing}

- Centralisation of clearing can bring large benefits but it dramatically increases the concentration of risk and requires improving safeguards. However, the run to centralisation should be made conditional on the verification of specific circumstances (such as liquidity, availability of prices, external risks, etc.). Not all standardised products can be centrally cleared, also in accordance with our proposed definition for 'standardisation' (see Box 1). A mandatory solution may weaken the network infrastructure by fostering adverse selection and raising huge moral hazard issues. The control of operational risk will crucial in the management of these platforms.

- A minimum level of interoperability between CCPs - as well as open and nondiscriminatory access to the platforms - is complementary to the process of centralisation of clearing. It allows competition in servicing costs, spreading best practices in risk and crisis management and improving market entry and default procedures, by introducing specific arrangements between these institutions. Interoperability can avoid market segmentation, but it raises two huge problems with its implementation: knock-on effects and moral hazard. The model of governance should be user-oriented, if the market does not invest in a userownership model.

- Centralisation of clearing can be an efficient solution for some asset classes that fit with eligibility requirements, but it cannot be the solution for all OTC derivatives. In effect, the practice of bilateral clearing will continue because the markets need it, and unnecessary charges will only create insufficient incentives to use the best clearing services. Bilateral and central clearing solutions do not imply that one model is better than another (Bliss \& Steigerwald, 2006); therefore, solutions that favour one system for all derivative products should not be put in place. In effect, for some classes of products the market was already pushing for centralisation of clearing. Policy-makers and financial institutions should work 
to improve collateral requirements in bilateral transactions in order to efficiently redistribute counterparty risk and shield the system from pro-cyclical effects.

- For bilateral transactions, even if stricter margin requirements may be economically justified (for initial margins only; but for variable ones, the market should decide), stricter capital requirements also for non-financial companies may be harmful. Unsustainable costs may push companies to modify their business models or to reduce their core business hedges. Capital charges help to discourage the use of derivatives but they do not concretely increase the safety of the transaction (capital is subject to other creditors' claims, etc.) and they do not seem to reflect the rationale of the transaction. Outsourcing collateral management and providing additional collateral (with segregated independent amounts) to dealers - especially for non-financial companies - can substantially increase the efficiency of collateral arrangements and the resilience of bilateral transactions without mandating inefficient capital charges. An efficient combination of stricter collateral arrangements (higher quality, amounts and legal segregation), daily calls for collateral and 'independent amounts' may create a high level of safety - similar to CCP - without affecting customisation and market liquidity.

- Centralisation towards organised venues, such as exchanges, may create a dramatic cut of customised financial products, which may make it difficult to find alternative solutions able to cope with a specific risk profile. In addition, some aspects of OTC derivatives may not be 'standardisable' in the same way as exchange-traded products are. Dealers' platforms are still the principal venue where standardisation and customisation find their best combination.

\section{Transparency and Supervision}

- The market for OTC derivatives is systemically important as the uncollateralised exposure (a small part of the notional value) is highly volatile and related to the underlying risk, which cannot be completely monitored. Sudden market moves may amplify negative effects, triggering liquidity crises and potential domino effects. Risk is concentrated in a few global financial institutions, which are 'too big to fail' or 'too interconnected to fail' and therefore need to be strictly supervised.

- The derivatives market is structurally affected by the pro-cyclical aspects and suffers from the opacity of counterparties' real net exposures. Transparency, therefore - more than any other solution - plays a crucial role in the OTC derivatives market. Opacity around uncollateralised net exposure and unsecured lines of big financial institutions may trigger mechanisms of adverse selection that freeze the financial system, such as occurred, for instance, in the interbank credit market in October 2008. A two-tier system, providing aggregate data to the public and disaggregated information only on a confidential basis to the authorities, seems a solution that preserves the business without affecting financial stability.

- Trade repositories (or data repositories) should provide high-quality data services and can work efficiently in a competitive environment, but there is no clear need for mandating regional repositories. Their role, then, would be different from the one covered by CCPs, since they may provide public aggregate and granular data for the market, plus single-name data for regulators (on a confidential basis) on bilaterally and centrally-cleared transactions. Regulators should verify with market participants if technologies and data formats allow concentrating data across asset classes in one data repository.

- The EU and US proposals to reform the OTC derivatives market share similar objectives but they lay out two different roads to achieve them. Striking divergences, if not specifically 
addressed, may shape markets in such ways that large space is left for regulatory and supervisory arbitrage. For instance, the US exemption granted to trades done for hedging purposes may stimulate non-financial European companies to move part of their business in the US, if Europe approves a legislative text without exemptions or stricter requirements.

To sum up, despite the original intention of converging on common rules for OTC derivatives, the final result of current proposals seems to be going in the opposite direction. The commitment to common objectives at G-20 level may actually be discarded, and Europe may adopt tougher solutions than the US. The risk of regulatory and supervisory arbitrage is high and it could be a source of instability in the years to come. Uniform and efficient regulatory actions, as well as international cooperation, may avoid this inefficient disequilibrium. In any case, regulators around the world will not leave the OTC derivatives market 'unregulated'. Their major concern with the regulation of OTC derivatives instruments is to strike the right balance between the limits set by the regulatory intervention and the freedom of market forces to lead markets - if wisely guided - towards efficiency. The ability of the market to tailor financial products to specific needs through financial innovation should be preserved, in order to support economic growth and to diffuse the benefits throughout the entire society. 


\section{References}

Acharya, Viral V. and Matthew Richardson (2009), Restoring Financial Stability. How to Repair a Failed System, Hoboken, NJ: John Wiley \& Sons.

Akerlof, G.A. (1970), “The market for 'lemons': Qualitative uncertainty and the market mechanism", Quarterly Journal of Economics, Vol. 84, No. 3, August, pp. 488-500.

Behof, J.B. (1993), "Reducing credit risk in over-the-counter derivatives", Economic Perspectives, Federal Reserve Bank of Chicago, pp. 21-31.

Biais, Bruno and Richard C. Green (2007), "The Microstructure of the Bond Market in the $20^{\text {th }}$ Century", August (available at http://idei.fr/doc/wp/2007/bondmarket.pdf).

BIS (Bank for International Settlements) (2007), New developments in clearing and settlement arrangements for OTC derivatives, Committee on Payment and Settlement Systems (CPSS), Basel, March.

(2009), OTC derivatives market activity in the first half of 2009, Monetary and Economic Department, Basel, November.

BIS and IOSCO (Bank for International Settlements and International Organisation of Securities Commissions) (2004), Recommendations for Central Counterparties, Committee on Payment and Settlement Systems and Technical Committee of the International Organization of Securities Commissions, Basel and Madrid, November.

Bliss, Robert R. and George G. Kaufman (2005), Derivatives and Systemic Risk: Netting, Collateral, and Closeout, Federal Reserve Bank of Chicago, WP 2005-03, 10 May.

Bliss, Robert R. and C. Papathanassiou (2006), "Derivatives clearing, central counterparties and novation: The economic implications", March (http://www.jscc.co.jp/en/ccp12/materials/docs/3.pdf).

Bliss, Robert R. and Robert S. Steigerwald (2006), "Derivatives clearing and settlement: A comparison of central counterparties and alternative structures", Economic Perspectives, 4Q/2006.

Cecchetti, Stephen G., Jacob Gyntelberg and Marc Hollanders (2009), "Central counterparties for over-the-counter derivatives", BIS Quarterly Review, September.

CESR (Committee of European Securities Regulators) (2009), "Classification and identification of OTC derivative instruments for the purpose of the exchange of transaction reports amongst CESR members", Consultation paper, 22 July.

CESR-ECB (Committee of European Securities Regulators and European Central Bank) (2009), "Recommendations for Securities Settlement Systems and Recommendations for Central Counterparties in the European Union", Paris and Frankfurt, May.

CPSS (Committee on Payments and Settlements) (2007), "New developments in clearing and settlement arrangements for OTC derivatives", Bank for International Settlements, Basel, March.

CPSS and IOSCO (Committee on Payments and Settlements and International Organisation of Securities Commissions) (2001), "Recommendations for securities settlement systems", Basel and Madrid, November.

Crawford, Bradley (1993), "The Legal Foundations of Netting Agreements for Foreign Exchange Contracts", 22 Canadian Business Law Journal. 
CRMPG III (Counterparty Risk Management Group) (2008), Containing Systemic Risk: The Road to Reform, Report of the CRMPG III, 6 August.

Culp, Christopher L. (2009), The Treasury Department's Proposed Regulation of OTC Derivatives Clearing and Settlement, Chicago Booth Research Paper No. 09-30, University of Chicago, July.

Dale, Richard (1998), "Risk Management in US Derivative Clearing Houses", Yearbook of International Financial and Economic Law.

Danielsson, J. and H.S. Shin (2003), "Endogenous Risk", in Peter Field (ed.), Modern Risk Management: A History, London: Risk Books (available at http://hyunsongshin.org/www/risk1.pdf).

Darby, Michael R. (1994), Over-the-counter derivatives and systemic risk to the global financial system, NBER Working Paper No. 4801, National Bureau of Economic Research, Cambridge, MA, July.

De Long, Bradford J., Andrei Shleifer, Lawrence H. Summers and Robert J. Waldman (1990), "Noise Trader Risk in Financial Markets", Journal of Political Economy, Vol. 98, No. 4.

Deutsche Borse Group (2009), The Global Derivatives Market. A Blueprint for Market Safety and Integrity, White Paper, September.

Duffie, Darrell (2009), How should we regulate derivatives markets?, Briefing Paper No. 5, PEW Financial Reform Project (available at www.ssrn.com).

Duffie, Darrell and Rohit Rahi (1995), "Financial Market Innovation and Security Design: An Introduction", Journal of Economic Theory, Vol. 65, No. 1.

Duffie, Darrell and Haoxiang Zhu (2009), Does a Central Clearing Counterparty Reduce Counterparty Risk?, Graduate School of Business Research Paper, No. 2022, Stanford University, February.

Duffie, Darrell, Ada Li and Theo Lubke (2010), Policy Perspectives on OTC Derivatives Market Infrastructure, Federal Reserve Bank of New York Staff Reports, No. 424, January.

ECMI (European Capital Markets Institute) (2009), Statistical Package, December (www.eurocapitalmarkets.org).

ESCB-CESR (European System of Central Banks and Committee of European Securities Regulators) (2009), "Recommendations for securities settlement systems and central counterparties in the European Union", May.

European Central Bank (2009), "OTC derivatives and Post-trading Infrastructures”, September.

European Commission (2009a), "Ensuring efficient, safe and sound derivatives markets", $\operatorname{COM}(2009), 332$ final, Communication from the Commission, July.

(2009b), "Ensuring efficient, safe and sound derivatives markets", SEC(2009), 905 final, Staff Working Paper, July.

(2009c), "Possible Initiatives to enhance the resilience of OTC Derivatives Markets", SEC (2009), 914 final, July.

(2009d), "Ensuring efficient, safe and sound derivatives markets: Future policy actions", COM (2009), 563 final, Brussels, October. 
(2009e), "Summary of the consultation on: Possible initiatives to enhance the resilience of OTC Derivatives Markets", Internal Market and Services DG, October.

Financial Times (2009), "Morgan Stanley battles over China derivatives", 28 October (http://www.ft.com/cms/s/0/e222bd1a-c3f7-11de-8de6-00144feab49a.html).

Fitch Ratings (2009), "Derivatives: A Closer Look at What New Disclosures in the U.S. Reveal", Special Report, Credit Policy, 22 July.

FSA (Financial Services Authority) (2009a), “The Turner Review”, March.

FSA (Financial Services Authority) and HM Treasury (2009b), "Reforming OTC Derivatives Markets. A UK Perspective", December.

FSB (Financial Stability Board) (2008), Report on Enhancing Market and Institutional Resilience, Follow-up on implementation, 10 October, p. 6.

FSB (Financial Stability Board) (2009), Improving Financial Regulation, Report of the FSB to G20 Leaders, 25 September, p. 10.

G-20 (2009), "Declaration on strengthening the financial system", London Summit, 2 April (http://www.londonsummit.gov.uk/resources/en/PDF/annex-strengthening-fin-sysm)

G-30 (2009), Financial Reform. A Framework for Financial Stability, Report of the Group of Thirty, 15 January, p. 53.

Glass, Adam W. (2009), "The regulatory drive towards central counterparty clearing of OTC credit derivatives and the necessary limits on this", Capital Markets Law Journal, Vol. 4, No. S1, June.

Gonzalez-Hermosillo, Brenda (1994), The Microstructure of Financial Derivatives Markets. Exchange-Traded versus Over-the-Counter, Bank of Canada, March.

Goodhart, Charles et al. (2008), "The Fundamental Principles of Financial Regulation”, Geneva Reports, Preliminary Conference Draft, ICMB-CEPR.

Grensted, Simon (LCH.Clearnet) (2009), "OTC Derivatives: Catching the train to centralization", presentation at ECMI seminar, 20 November (http://www.eurocapitalmarkets.org/system/files/ECMI_Grensted_20nov09.pdf).

Grossman, Sanford J. and Joseph E. Stiglitz (1980), "On the Impossibility of Informationally Efficient Markets”, American Economic Review, Vol. 70, No. 3, June, pp. 393-408.

Hasenpusch, Tina P. (2009), Clearing Services for Global Markets, Cambridge: Cambridge University Press.

Holmstrom, Bengt (1979), "Moral Hazard and Observability", The Bell Journal of Economics, Vol. 10, No. 1, pp. 74-91, Spring.

Hull, John C. (2006), Options, Futures and Other Derivatives, Sixth Edition, PHI.

IOSCO (International Organisation of Securities Commissions) (2009), Unregulated Financial Markets and Products, Final Report, Madrid, September.

ISDA (International Swaps and Derivatives Associattion) (2009), "Margin Survey", New York (available at www.isda.org).

(2009), “Operations Benchmarking Survey”, New York (available at www.isda.org).

(2010a), "Independent Amounts", Release 2.0, New York, 1 March. 
(2010b), "Market Review of OTC Derivative Bilateral Collateralization Practices", Release 2.0, New York, 1 March.

Jomadal, B.K. (2007), The ISDA Master Agreement. The Rise and Fall of a Major Financial Instrument, University of Westminster (available at www.ssrn.com).

JP Morgan (2010), "Global Banks - Too Big to Fail? Running the Numbers", Europe Equity Research, 17 February.

Kraakman, Reinier H. (1986), "Gatekeepers: The Anatomy of a Third-Party Enforcement Strategy", Journal of Law, Economics and Organization, Vol. 2, No. 1, Spring.

Ledrut, Elisabeth and Christian Upper (2007), "Changing post-trading arrangements for OTC derivatives", BIS Quarterly Review, December.

Lee, Ruben (2010), The Governance of Financial Infrastructure, Oxford Finance Group, January (available at http://www.oxfordfinancegroup.com).

Markit (2009), "Comments on ESCB/CESR Draft Recommendations for Central Counterparties for OTC derivatives", 16 April.

Milgrom, Paul and John Roberts (1992), Economics, Organization \& Management, New Jersey: Prentice Hall Inc.

NERA Economic Consulting (2007), The European Equities Post-trading Industry: Assessing the Impact of Market and Regulatory Changes, City Research Series 11, February.

Nystedt, Jens (2004), Derivative Market Competition: OTC Markets Versus Organized Derivative Exchanges, IMF Working Paper 04/61, International Monetary Fund, Washington, D.C., April.

OCC (Office of the Comptroller of the Currency) - Administrator of National Banks, "OCC's Quarterly Report on Bank Trading and Derivatives Activities - Second Quarter 2009" (available at http://www.occ.treas.gov/ftp/release/2009-114a.pdf).

Oxera (2008), Building efficiencies in post-trade processing. The benefits of same-day affirmation, Report for Omgeo, June.

Pagano, Marco (1989), "Trading Volume and Asset Liquidity", Quarterly Journal of Economics, Vol. 104, No. 2, May, pp. 255-274.

Pindyck, Robert S. and Daniel L. Rubinfeld (2004), Microeconomics, $6^{\text {th }}$ edition, Prentice Hall.

Rausser, Gordon, William Balson and Reid Stevens (2009), "Centralized Clearing for Over-theCounter Derivatives", University of California (available at www.ssrn.com).

Segoviano, Miguel A. and Manmohan Singh (2008), Counterparty Risk in the Over-TheCounter Derivatives Market, IMF Working Paper 08/258, International Monetary Fund, Washington, D.C., November.

Singh, Manmohan and James Aitken (2009), Counterparty Risk, Impact on Collateral Flows, and Role for Central Counterparties, IMF Working Paper 09/173, International Monetary Fund, Washington, D.C., August.

Stout, Lynn A. (2009), "Regulate OTC Derivatives by Deregulating Them", Regulation, Banking \& Finance, Fall.

Swan, Edward J. (2000), Building the Global Market: A 4000 Year History of Derivatives, London: Kluwer Law. 
Volcker, P. (2010), Statement before the Senate Committee on Banking, Housing and Urban Affairs of the United States, Hearing on Prohibiting Certain High-Risk Investment Activities by Banks and Bank Holding Companies, 2 February.

US Treasury (2009), "Financial Regulatory Reform - A New Foundation: Rebuilding Financial Supervision and Regulation", 30 June (followed by the Administration's proposal on 11 August 2009).

Yallop, Mark (2008), The Future of the OTC Markets, ICAP White Paper, ICAP, London, November.

Whish, R. (2005), Competition Law, $5^{\text {th }}$ ed., Oxford: Oxford University Press 


\section{Abbreviations}

BIS Bank for International Settlements

CCP Central Counterparty

CDO Collateralised Debt Obligation

CDS Credit Default Swap

CESR Committee of European Securities Regulators

CFTC Commodity Futures Trading Commission

CPSS Committee on Payment and Settlement Systems (of the BIS)

CRD Capital Requirements Directive

DCO Derivative Clearing Organisation

DTCC Depository Trust and Clearing Corporation

ECB European Central Bank

ESMA European Securities and Markets Authority

FSA Financial Services Authorities (UK)

GDP Gross Domestic Product

IOSCO International Organisation of Securities Commissions

ISDA International Swaps and Derivatives Association

MAD Market Abuse Directive

MiFID Markets in Financial Instruments Directive

MSP Major Swap Participant

OTC Over-the-Counter

SEC Securities and Exchange Commission

STP Straight-through-Processing 